\title{
Toward the Hypothesis of Cancer Xenogamous Origin and its Circle of Life
}

\author{
Sergey N.Rumyantsev \\ Department of Evolutionary Immunology, Andent Inc., Jersey City, New Jersey, USA \\ rumyan1@yahoo.com
}

\begin{abstract}
The failure of Cancer Crusade (1971-2012) revealed extraordinary need to elaborate of more productive paradigm of cancer. The goal of this article is to search and reveal epidemiological, clinical, genetic and immunological evidence of the entirely innovative hypothesis of the xenogamous origin and unique parasite subsistence of human cancer. The investigation was grounded on a multidisciplinary integrative reassessment and reinterpretation of both the current and newest data on cancer from the viewpoint of recent achievements in epidemiology, immunology, molecular interspecies ecology and the theory of biological evolution. It is shown that the multiplicity of traits that belong to cancer are performed by a causative agent of the disease, an unique biological entity that evolved to invade the human body and to subsist in it at the expense of the materials, energy and functions of the invaded organism over consecutive stages of cancer subsistence, beginning from the invasion of victim's with cancerous gamete and finishing with the sexual transmission of cancer among people. The results achieved and the conclusions reached provide a new framework and new landmarks for understanding cancer epidemics and encourage new proposals for cancer prevention and therapy by means of newly oriented genetic, immunological and molecular ecological approaches.
\end{abstract}

Keywords: Hereditary Cancer / Cancer Embryogenesis / Genome Intrusion / Sexual Transmission / Xenogamy / Selfish Genes

\section{INTRODUCTION}

In spite of impressive efforts both worldwide and in regional communities, cancerous disease continues to distress humankind as a growing and unsolved problem in world health. Almost 14.1 million new cases of cancer occur annually, and 8.2 million deaths are attributed to the disease each year [1;1]. However, the efficacy of the means currently exploited for cancer prevention and treatment appears to be extraordinary low. Furthermore, the 80-year paradigm of the origin and pathogenesis of cancer, the 'somatic mutation hypothesis' [2], has appeared to be impotent [3]. It appears to be unable to decipher the origin of principal traits of the disease, its pathogenesis and the mode of epidemic spread [4]. Compared to the areas in which medical research was most successful, cancer presents fundamentally different challenges. Meager progress in the knowledge of cancer calls for new research approaches. New insights in the biology, origin, circle of life, pathogenesis, immunology, clinical progression and epidemic spread of cancer are sorely needed [3;5-7].

The dire need for principally new approaches to the construction of appropriate knowledge of cancer has induced the presentation of a radically different view on the origin, pathogenesis, immunology, genetics and pandemic spread of human cancer: the hypothesis of a xenogamous parasite origin and sexual transmission of human cancerous disease $[4 ; 8]$. According to the hypothesis, cancerous disease is a type of invasive disease that is caused by a specialized cancerous parasite that invades the genome of an attacked human body. The presented article helps reconsider closely conjugated issues of a set of traits of human cancerous disease from the view point of the new hypothesis.

\section{MAterials AND MethodS}

The goal of this article was to search and reveal far more exhaustive epidemiological, clinical, genetic and immunological evidence of the new hypothesis regarding epidemiological and clinical bases of cancerous disease. The investigations were grounded on a multidisciplinary integrative reassessment and reinterpretation of the current data on cancer from the viewpoint of recent achievements of epidemiology, immunology, molecular ecology and the theory of biological evolution. It should be noted that although the present article is devoted to conclusive 
version of 'The Hypothesis of Cancer Xenogamous Origin and Circle of Life', the completeness of its evidence was ensured by the inclusion in the text of relevant excerpts out of previously published separate discoveries each of which revealed various evidence of origin and current subsistence of cancer. Publication of whole hypothesis without these inclusions could crash the complex of its evidence. The investigations were based on a multidisciplinary integrative reassessment and reinterpretation of relevant current data about cancer according to sufficient details of methods described in previous publications [4-6;8-15] The focus was on the functions of hereditary immunity in cancer epidemiology, heritability and pathogenesis over consecutive stages of cancer subsistence. Special attention was given to hereditary immunity to physiological agents and the phenomenon of hereditary immune mosaics [16;17].

\section{RESULTS AND DISCUSSION}

\subsection{Hereditary Cancer}

Several studies have suggested a role of host genetics in cancer immunity and susceptibility. Countless candidate gene studies and many genome-wide linkage scans have been conducted. However, there is considerable inconsistency across these studies. Crucial support for genetic immunity/susceptibility to cancer has been provided by epidemiological observations in families.

\subsection{Family Studies}

The existence of hereditary immunity to cancerous diseases was unknown before the beginning of $20^{\text {th }}$ century. Alfred Scott Warthin (Figure 1) was the first person whose observations convinced him convinced that there existed hereditary immunity to cancer and hereditary susceptibility to it. $\mathrm{He}$ worked up the histories of several generations of stable families and presented the first description and genealogy of classic cancer-prone and cancer-immune families in the early 1900s [18].

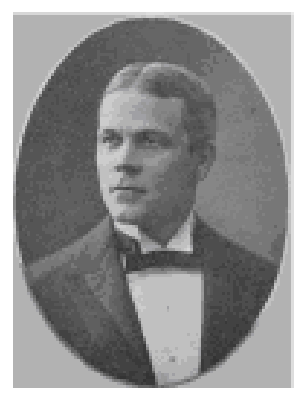

Figure1. Aldred Scott Warthin (1866-1931), MD, PhD Chairman of the Department of Pathology, University of Michigan at Ann Arbor

The most prone family (Figure 2) was of German origin (Family G), and the members of the family and fourth generations have continued to live in Washtenaw County, Michigan, in the neighborhood of Ann Arbor. The first study of the influence of heredity on the development of carcinoma was taken from the records of the pathological laboratory of the University of Michigan over the period 18951913. [18].

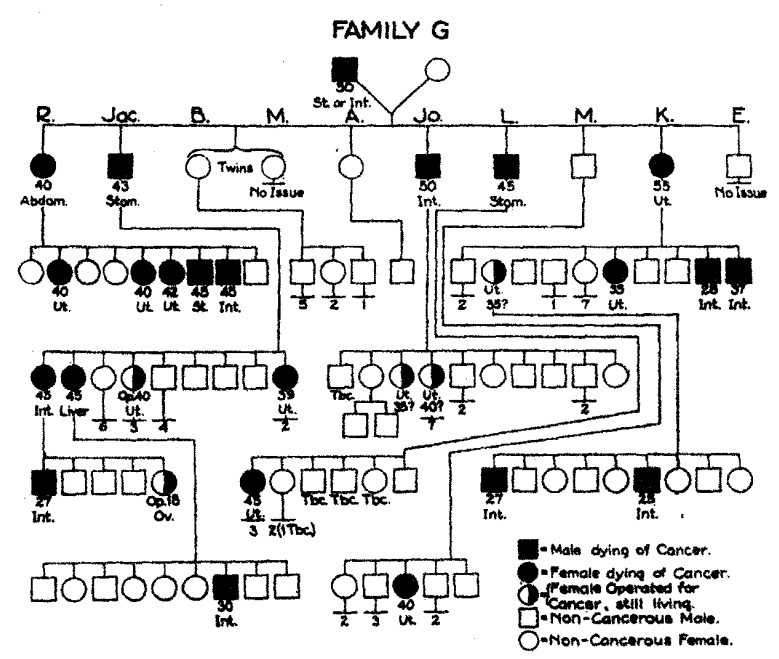

Figure2. Complete genealogical table of Family $G$, comprising all descendants of the original grand-paternal settler [19] 
Until 1913, of the 48 traced descendants of a cancerous grandfather, 15 had developed cancer, and 2 others presented with neoplasms that were not shown to be malignant. Some members died before they were 25 years old.

This pioneer study provided genetic oncology with important notes. It seemed to show a marked susceptibility or immunity to carcinoma in cases of certain family generations and family groups. It also seemed to show that susceptibility is frequently associated with a marked susceptibility to tuberculosis and with lowered fertility.

The multiple occurrence of carcinoma in a family generation was practically always associated with its occurrence in a preceding generation, and the family tendency was found to be more marked when carcinoma occurred in both maternal and paternal lines. Family susceptibility to carcinoma was shown particularly in the case of carcinoma of the gastrointestinal tract and the uterus. In a family showing the occurrence of carcinoma over several generations, a decided tendency for the neoplasm to develop at an earlier age in successive generations was shown, and a special degree of malignancy was often noted in such cases.

When this study was reported, it was met with little favor among surgical writers, particularly among those interested in propaganda for the prevention of cancer. In some of the literature related to this propaganda, it was said that there was no evidence for the existence of a familial susceptibility to cancer. [18].

The results achieved present the first description and genealogy of classic cancer-prone and cancerimmune families. The facts that were drawn by the researcher from cancer surgical histories and operative materials revealed a surprisingly high number of patients whose family history revealed multiple occurrences of carcinoma, in some cases. The facts were so striking that the author introduced for this phenomenon the term "cancer family". The results of the subsequent study of hereditary cancer was published in 1925 [19]. When this study was reported, it was met with little favor among surgical writers, particularly among those interested in propaganda for the prevention of cancer. In some of the literature related to this propaganda, it was stated that there was no evidence for the existence of a familial susceptibility to cancer. Later, research on the same family (Figure 3) was continued [20].

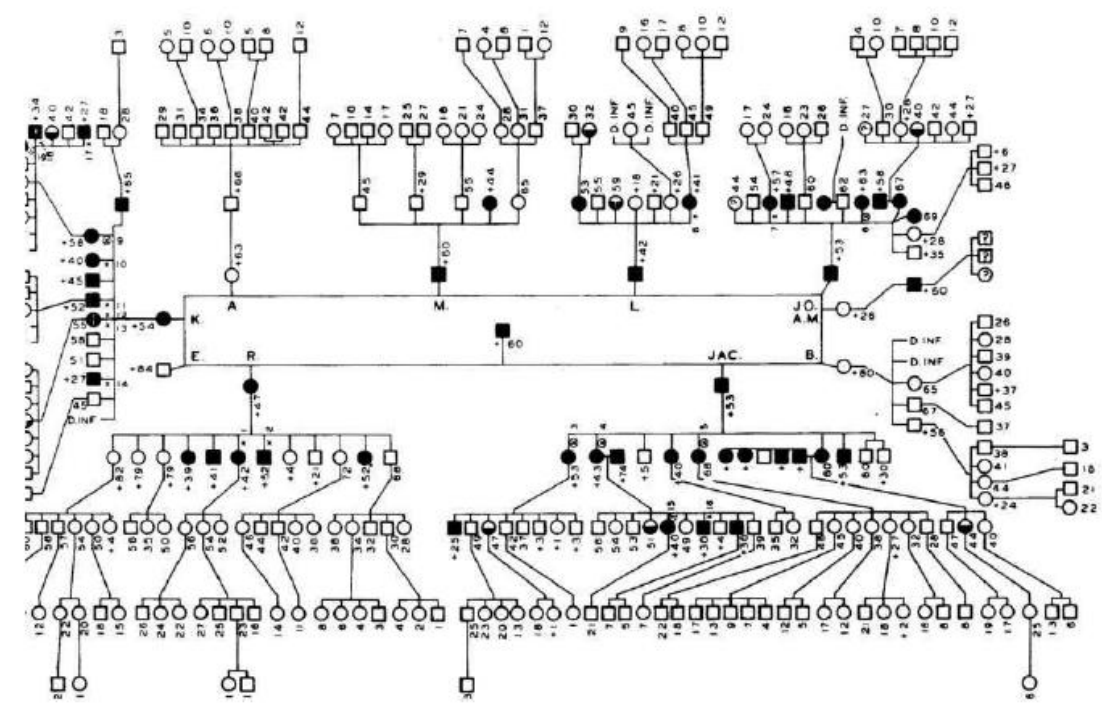

Figure3. Cancer of the Warthin Family in 1936. Successive generations appear in successive rectangles moving outward. The first child of the second generation was $R$. The order of the children in this and subsequent generations is shown counter-clockwise on the diagram [20].

It should be noted that at the time of the first report, in 1913 [18], 15 of the 48 traced descendants of a cancerous grandfather had developed cancer (a cancer incidence of 31.81 percent). However, at the time of the final report, in 1936 [20], the family included 305 individuals, of whom 41 had developed malignant neoplasms, an incidence of 13.44 percent. This 2.4 -fold decrease in the intensity of cancerous epidemics is also observed by a comparison of Figures 8 and 9. The findings suggest that the observed decrease in cancer incidence arose as a result of the elimination of susceptible people by an epidemic observed over nearly 3 generations. 
For many subsequent decades, little attention was given to the heredity in "cancer families". Then, in the 1960s, Henry T. Lynch described two large cancer kindreds and reported the first family with the complex of associated malignant diseases, which is now called Lynch Syndrome [21]. Over the $20^{\text {th }}$ century, insight into the inheritance of the phenomenon was concentrated on Lynch Syndrome. However, from the late 1960s until the beginning of the $21^{\text {st }}$ century, progress in understanding Lynch Syndrome continued to be slow.

\section{ETHNic OBSERVATIONS}

\subsection{Populations Disparity in Cancer Prevalence}

The rates of cancer incidence (Figure 4) show wide variations among populations. The rates for all cancer sites in males revealed $>8$-fold differences that ranged from 493.8 per 100,000 in Tasmania, Australia to a low of 59.1 in The Gambia, which also shows the lowest rates for cancer of the colon, rectum, pancreas, bronchus, lung, thyroid gland, myeloid leukemia, bladder, tongue, mouth and testis. Rates for U.S. males were 351.3 for blacks (SEER) and 330.4 for whites [22]. One can expect that the key to the origin of cancer will be found in the ecology of The Gambia innate ethnos, which provides a more than 5-fold resistance to cancer in contrast to U.S. blacks and whites. Prostate cancer, one of the most common cancers in men, is particularly frequent in men of African origin. Prostate cancer incidence rates in African Americans are $>1.5$-fold greater than the rates in Americans of European origin [23].

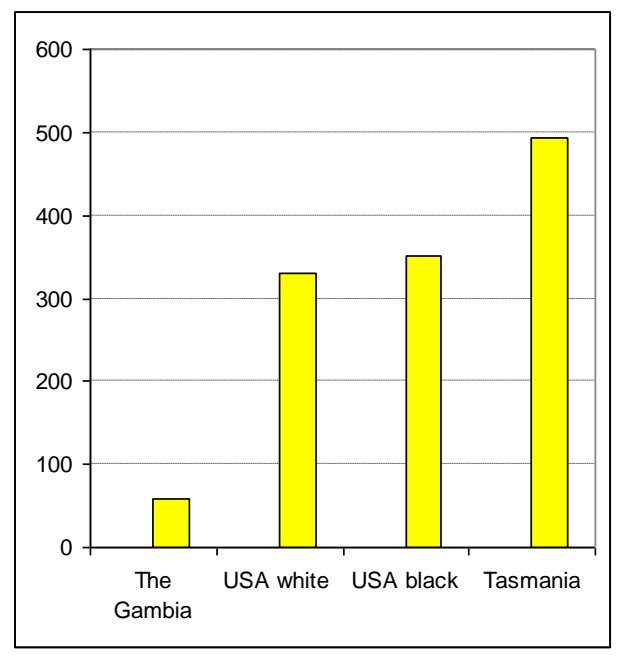

Figure4. Ethnic variation in the rates of cancer incidence. According to [24]

The rates used (Figure 5) are the number of cancer deaths per 100,000 populations. They are ranked from the highest to the lowest [22]. The data revealed a four-fold difference between the lowest (54.4 in Thailand) and the highest (235.4 in Hungary) male cancer mortality rates. The five most cancerous countries includes Hungary, Luxembourg, Belgium, France and Uruguay. The five least cancerous countries include Mexico, Ecuador, Panama, Thailand and Kuwait [22]. One can suppose that in contrast to Hungary, the population of Thailand could be deemed immune to cancer.

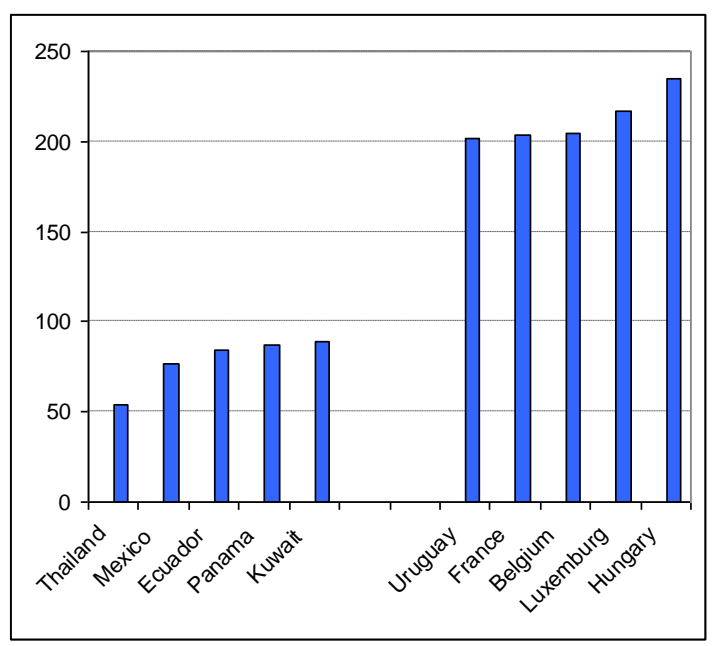

Figure5. Variation in male cancer mortality rates among different populations, according to [24] 
The largest ratios of the highest rates to the lowest rates in worldwide cancer incidence among males were for melanoma of the skin, nasopharynx, and larynx, with ratios of 289, 285, and 204, respectively (Table 1).

Table1. The ratios of the highest rates to the lowest rates in worldwide cancer incidence, according to [24]

\begin{tabular}{|l|l|l|c|}
\hline \multirow{2}{*}{ Cancer } & \multicolumn{2}{|c|}{ The values of rates per 100,000 } & \multicolumn{1}{c|}{ Lowest rate } \\
\cline { 2 - 4 } & \multicolumn{1}{|c|}{ Highest rate } & 0.1 (Kuwait, Thailand) & 289 \\
Skin melanoma & 28.9 (Australia) & 0.1 (Quito, Ecuador) & 285 \\
Nasopharynx & 28.5 (Hong Kong) & 0.1 (Qidong, China) & 204 \\
Larynx & 20.4 (Basque Country) & 0.8 (Qidong, China) & 127.5 \\
Prostate & 102.0 (Atlanta, Georgia) & 1.0 (The Gambia) & 119.1 \\
Lung & 119.1 (Maoris, NZ) &
\end{tabular}

For melanoma of the skin, the area reporting the highest rate was the Australian Capital Territory, with 28.9 per 100,000; the lowest rate, 0.1, was reported among Kuwaitis in Kuwait and among persons in Khon Kaen, Thailand. For nasopharynx cancer, the highest rate was 28.5 in Hong Kong, whereas the lowest was 0.1 in Quito, Ecuador. For larynx cancer, the highest rate was 20.4 in Basque Country, Spain, and the lowest rate, 0.1, was for men in Qidong, China. Prostate cancer rates were highest for black men in Atlanta, Georgia (102.0) and lowest in Qidong, China (0.8 per 100,000). The worldwide range in lung cancer incidence among men ranged from a high of 119.1 in New Zealand Maoris to 1.0 per 100,000 in The Gambia. U.S. black men in New Orleans experienced a lung cancer rate of 115.9, just lower than that for Maoris in New Zealand.

\subsection{Racial Differences of Cancer Prevalence}

Interracial differences compose one of the main riddles of cancer manifestations that should be decoded. For instance, the rates of male skin and pancreas cancer incidence referenced by two primary sites and races cannot be explained from the viewpoint of current paradigm.

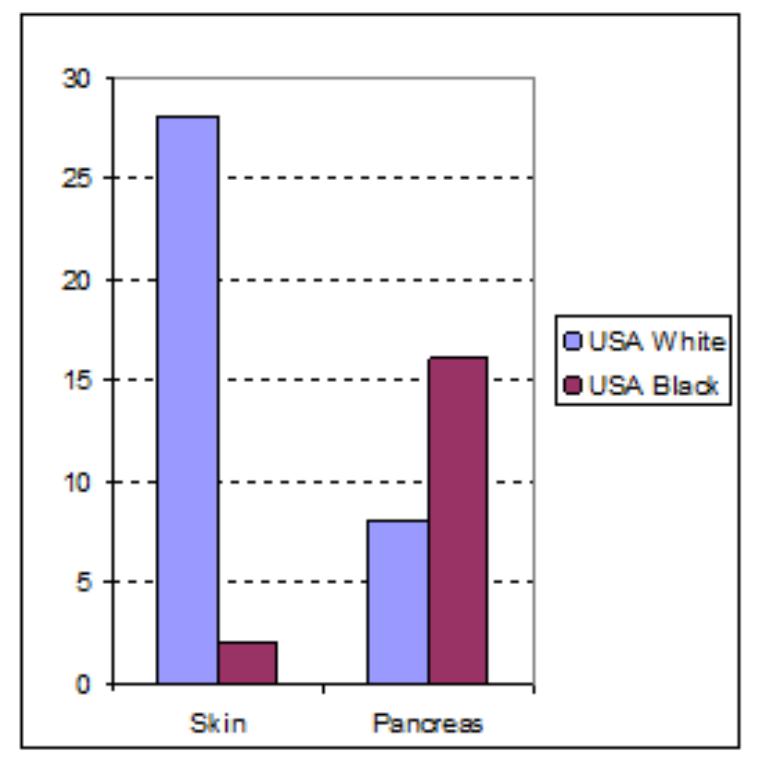

Figure6. Opposite rates of male cancer incidence by primary site and race*, according to [22]. *Rates are per 100,000 persons of the 2000 U.S. standard population.

The above-discussed new observations (Figures 5 and 6 and Table 1) are intriguing but seem mysterious in light of the orthodox postulates about cancer. This is one of the main riddles of cancer manifestations that should be decoded. At the same time, these observations videnced the existence of ethnoses (and persons) with very high grades of natural, i.e., genetic immunity to cancer and thus reveal important milestones in the way of deciphering both the origin of cancer and the genetic components of the disease pathogenesis. A more complete understanding of cancer's origin, pathogenesis and epidemic spread will come from the discovery of relevant subjects in opposite ethnic and racial groups. One of the milestones could be the traits of ethnoses and populations that reveal opposite values of the rates of cancer prevalence. Another milestone could be revealed by the analysis and comprehension of both individual and intra-individual diversity in natural immunity to cancer. 


\subsection{Twin Studies}

The study of cancer in twins should be of great value in the knowledge of genetic epidemiology, pathogenesis and treatment cancerous disease. However, little is known about these aspects of oncology Moreover, little has been done to explore this area. Twin studies on cancer focus on the heritability of cancer by via the analysis of monozygotic twins compared to dizygotic twins or siblings.

In the 10503 twin pairs from the old cohort, 361.7 cases of malignant cancer were identified, and 918 malignant cancers were identified in the 12883 twin pairs from the young cohort. When cancer sites with a total of at least 200 cases and at least one concordant twin pair (i.e., both twins affected) for the site were evaluated, specifically for cancers of the stomach, colon and rectum, lung, female breast, and prostate, as along with total cancer, profound genetic and/or nongenetic familial effects were identified in twins from the old cohort. Similar findings were obtained for twins in the young cohort for cancers of the prostate and female breast and for total cancer [25]. Genetic and nongenetic familial effects were also identified in twins from both cohorts for in situ cancer of the cervix.

In a retrospective cohort study of cancer among 35,271 twins and 74,199 singleton newborns with 336 and 691 cancer diagnoses, respectively, the relative risk of childhood cancer in twins compared with singletons was not significantly different from that among adult twins for cancers of the breast, prostate, testis, lymphatic system, thyroid, and large bowel. There was no overall differential in the three investigated groups of twins [26]. Identical twins are not as identical as was once thought, according to new studies of DNA.

A Swedish study compared female identical twins (who share all their genes) with female fraternal twins (who share approximately half their genes) to determine the extent to which differences in breast cancer incidence could be attributed to differences in genetic makeup [27]. The study found that genetic differences played a relatively minor role in breast cancer risk, suggesting that most differences among individuals in breast cancer risk were related to environmental factors. Even among identical twins, cancer in one twin usually was not accompanied by cancer in the other [25]. One twin might have gotten cancer when the other did not. Differences in cancer incidence and clinic manifestations could not be attributed to differences in genetic makeup.

The recent Nordic Twin Study of Cancer cohort is the world's largest prospective study on the subject [28]. It includes 18,680 monozygotic (MZ) and 30,054 dizygotic (DZ) same-sex male twin pairs. In contradiction to the above-discussed data, the study revealed that the cumulative risk for twins whose co-twin was diagnosed with prostate cancer was greater for MZ than for DZ twins across all ages. Among concordantly affected pairs, the time between diagnoses was significantly shorter for MZ than for DZ pairs. Genetic differences contributed substantially to variation in both the risk and the heritability of prostate cancer. Prostate cancer was previously thought to be the most heritable cancer, although little is known about how this genetic contribution varies across age. The secret of the above-considered controversies may be found in the earliest stages of cancerous invasion and cancer ontogeny (Sections 3.5. and 3.6).

\subsection{Genome Studies}

Countless candidate genes from host-genome studies and many genome-wide linkage scans have been proposed. However, there is considerable inconsistency across these studies.

\section{Cancerous Invasion}

\subsection{Contagious Invader of Cancer}

Human cancer, a causative agent of human cancerous disease, is a biological entity that evolved to invade the human body and to subsist in the genomes of its cells at the expense of the materials, energy and functions of the invaded organism. Over the circle of life, cancer exists sequentially in subcellular, unicellular and multi-cellular forms. It spreads between humans and intrudes in the genomes of human reproductive cells - either sperm or ova - that function as unicellular hosts of the parasite.

The core of cancer consists of a set of genes controlling physiological and ecological functions of the parasite over consecutive stages of it development and subsistence. It performs the functions of cancer genome. This kit of genes may contain, for instance, the known variants of BRCA genes (BRCA1 and 
BRCA2) every of which may participate in the induction among affected persons of colon cancer, pancreatic cancer, prostate cancer, breast cancer, ovarian cancer or probably other kinds of hereditary cancer. It consists of genes foreign to its prey and exists in the prey's genome as a xenogamous intruder. Its structure is able to control the performance of traits intrinsic to any other parasite, including nutrition and self-reproduction. Furthermore, cancer possesses many original adaptations to a parasitic way of life.

The multiplicity of traits that belong to human cancer is revealed by a cancerous contagion, a causative agent of the disease, i.e., a specialized biological entity that evolved to invade the human body and to subsist in the genomes of its cells at the expense of the materials, energy and functions of the invaded organism.

\subsection{Origin of Cancerous Contagion}

Cancer was initiated by the appearance of deviant cell lineages in the human body that habitual regulators of cell division and tissue growth are unable to control (Section 3.1.1.). The uncontrollability is predetermined by the constitutional immunity of cancerous cells to the mediators of the habitual regulation of cell division and tissue growth (Rumyantsev 2009b, Rumyantsev, 2009a). This intrinsic trait of cancerous cells is their ultimate evolutionary adaptation for carcinogenesis. Such deviant cell lineages appear in the human body as a result of genome transformation performed over the heterozygous crossbreeding between parental gametes with partially different (deviant) genotypes. In the xenogamous formation of a descendant's zygote, its genome becomes admixed with the deviant (carcinogenic) genes [5]. Xenogamous mating between members of genetically different species [29], subspecies, ethnoses and families was characteristic of the descent of humans and their further evolution as they wandered the world. This led to the intrusion of the human genome with components of deviant genetic information that induced intra-individual diversity of cell lineages [30]. Some of the cells appeared to have the main trait of cancerous cells and genetic immunity to habitual regulators of cell division.

\section{Stages of Cancerous Invasion}

The descent and consequent subsistence of human cancer includes the regular obligatory alternation of successive descendants, which form a hypothetical pathway of tumor development from the gametes-zygote to an advanced stage of cancer (Table 2). Cancerous intruders enter the human body in the form of reproductive cells by means of organs and functions of human reproduction.

Table2. Successive forms in cancer progression and subsistence, according to [9]; updated

\begin{tabular}{|c|c|c|c|c|c|c|}
\hline Parents & Genomic & Unicellula & & & Multicell & forms \\
\hline $\begin{array}{l}\text { Habitual } \\
\text { parent }\end{array}$ & $\begin{array}{l}\text { Habitual } \\
\text { parent's } \\
\text { genome }\end{array}$ & $\begin{array}{l}\text { Habitual } \\
\text { gamete }\end{array}$ & $\begin{array}{l}\text { Cancerous } \\
\text { zygote }\end{array}$ & \multirow[t]{2}{*}{$\begin{array}{l}\text { Earliest } \\
\text { cancerous } \\
\text { cells }\end{array}$} & \multirow{2}{*}{$\begin{array}{l}\text { Fetal } \\
\text { micro } \\
\text { locations } \\
\text { of cancer }\end{array}$} & \multirow[t]{2}{*}{ Tumors } \\
\hline $\begin{array}{l}\text { Cancerous } \\
\text { parent }\end{array}$ & $\begin{array}{l}\text { Cancerous } \\
\text { parent's } \\
\text { genome }\end{array}$ & $\begin{array}{l}\text { Cancerous } \\
\text { gamete }\end{array}$ & & & & \\
\hline
\end{tabular}

\subsection{Cancerous Sperm (CS)}

$\mathrm{CS}$ is a the sperm whose genome contains an invaded cancerous genome.

\subsection{Cancerous Ovum (CO)}

$\mathrm{CO}$ is an ovum whose genome contains an invaded cancerous genome.

The ubiquity of clonality, particularly of that observed in human biology [31] and pathology [16;17;32], suggests the initiation of intraindividual diversity in the stages of both male and female gametes. This supposition could help explain some controversies in the inheritance of human cancer.

\subsection{Cancerous Zygote}

According to well-established knowledge [33], every new entity is initiated by the process of fertilization involving the fusion of male and female gametes to form a zygote, the unicellular form of 
the entity born during the fusion of relevant gametes and their genomes. In the case of carcinogenic fertilization, the zygote's genome contains carcinogenic components. A cancerous zygote may be formed either by the intrusion of cancerous sperm in habitual ova or by the intrusion of habitual sperm inside cancerous ova. Both variants lead to the formation of a cancerous zygote. The coexistence in a xenogamous zygote of both habitual and deviant, e.g., cancerous genes is a result of a well-known mechanism of heterozygous interbreeding, which is responsible for the formation of the intraindividual biodiversity that is characteristic of any type of human pathology [12;16;17]. After the development of the zygote, the descendant organism consists of both habitual and deviant cells. The activity of cancerous genes leads to the appearance in the invaded human body of a set of deviant cell lineages provided with relevant cancerous abilities. They are able to resist the habitual regulation of cell division and tissue growth and the victim's immune response. The lineages and their extracellular associates first form the micro-locations of cancer units and then form their clinically detectable locations, i.e., the cancerous tumors.

The exceptional foreignness of cancer for its host should be emphasized. All cancer looks alien in afflicted bodies. This is true of both the bodies of cancerous tumors (Figure 7) and their microscopic cellular tissue structures.

The gross and microscopic features of cancerous cells presented by [34] and any other form of cancer disease also attest to the foreignness of cancerous malignancy: The cancer cells look abnormal and foreign under a conventional light microscope. Although they are considered versions of cells that compose the tissue of the supposed cancer origin, in reality, light microscopy cannot identify the tissue or site of the malignancy origin [35].

There are plenty of various morphological and physiological manifestations of the foreignness of cancer to its prey. Some of them may be traits similar but not identical to those of infectious and parasitic diseases. Their influence is revealed in other features of cancer and both unique and universal all-pathological traits of malignancy. The presence of cancerous foreignness was evidenced in lung and breast cancers (over 90\%) by dogs' scent [36]

\section{EMBRYOGENESIS OF CANCER}

The divergence between normal and cancerous cell clones should begin far before antenatal embryogenesis. The earliest cancerous cells are formed in fetal micro-locations dispersed around the body, in accordance with general rules of the embryonic differentiation of tissues and their dislocations inside the appropriate organs [13].

\subsection{Hereditary Immunity of Cancer to Human Regulatory Management}

Any living being is constitutionally provided with a physiological system that maintains a normal body structure within its genetically predetermined shape, size and function. A special part of this very important and effective system is dedicated to managing the starting and revival of body structures and functions on molecular, sub-cellular, cellular, tissue and organ levels. Habitual cells of normal organisms grow and divide to form new cells as the body needs them. When cells grow old and die, new cells take their place. The regulation is realized on the cellular level and performed by means of molecular humoral agents.

In the case of cancer invasion, this orderly process goes wrong. The mighty system of body management and maintenance appears to be impotent, even in relation to some of its initially smallest parts, the subunits of cancer. Cancerous cells grow and divide independently of habitual physiological management. That occurs because cancer cells and tissues possess absolute constitutional immunity to the agents of the habitual physiological management of cell division and tissue formation. The constitutional (hereditary) immunity of the cells against relevant physiological regulators can be created by structural incongruence between regulators and their receptors. The existence of such specific immunity is considered the obligatory prerequisite to malignity [6].

Cancer cells continue dividing and forming the masses of relevant tissue when the afflicted body does not need them. Furthermore, the cancerous cells of older generations do not die when their peers would. The extra cells form the masses of tissue called malignant tumors. This innate (constitutional) trait of cancerous cells is of great adaptive and pathogenic importance. This innate immunity of cancerous cells functions in all stages of cancer and maintains its initiation, development and subsequent progression. 


\subsection{Hereditary Immunity of Cancer to Human Immune Defense}

Human cancer invades its victim because there is no immunity. The malignant cells and tissues are inherently protected from destruction by cell and humoral mechanisms launched by the victim's lymphatic system of responsive immunogenesis. Cancerous cells are not recognized by the victim's immune system as non-self because their surface does not contain relevant molecules of the major histocompatibility complex that are essential to the antigen-processing pathway. Such traits allow the cancer to evade the surveillance performed by the victim's system of immunogenesis. This protection is predetermined by the germ line of the formation of cancerous cells directly from the zygote over the prenatal development of the afflicted organism [4]. This trait of cancer ontogeny is undoubtedly of evolutionary (genetic) adaptation, providing the parasite with a lifelong ability to escape rejection by the victim's immune response.

\subsection{Heterogenic Make-up of a Ripe Cancer}

The somatic mutation hypothesis allows the existence of only one cancerous cell clone in an affected body. The first doubts about this hypothesis were revealed by integrative analyses of epidemiological and clinical observations, [4] according to which the multiple cancers comprise two or more primary cancers occurring in an individual that originate from a primary site or tissue and are not an extension, a recurrence or metastasis [37].

Cancer patients have a $20 \%$ higher risk of developing a new primary cancer compared to the general population. Approximately one-third of cancer survivors aged $>60$ years were diagnosed more than once with another cancer. As the number of cancer survivors and older people increases, the occurrence of multiple primary cancers is also likely to increase [37-41]. Such observations prompted the idea of the possible existence of a number of appropriate clones in cancerous tissue. This means that as any other multicellular being does, cancer may contain a variety of different cells and associated extracellular structures that are under different genetic regulations and may perform different functions at different stages of cancer development $[4 ; 6]$. According to the xenogamous theory of carcinogenesis, any ripe cancer should consist of a number of subunits of various sizes that are positioned in different areas of the afflicted body. Each subunit contains cellular and tissue structures. In contrast to the somatic mutation hypothesis, the existence of a number of different clones in a cancer was recently well documented.

Recent studies [42], along with the set of data discussed above, allow us to suppose that as any other multicellular being does, cancer contains a variety of different cells that are under different genetic regulation and possess different behaviors. Cancer consists of a few functionally heterogeneous cell lineages that vary with respect to their distinctive structural or physiological functions and potentials. Heterogeneity within a tumor cell lineage may also determine the differences within the tumors and their locations. Cancer is able to maintain its structural stability through many generations, and the diversity of cancer composition remains stable over its sequential long-term propagation [42]. This means that both animal and human cancers have developed many adaptations that enable these aberrant lineages of mammalian cells to exist as a multicellular parasite $[4 ; 6]$.

Cancer cells are the driving force of tumor development and progression, but these transformed cells cannot do it alone. Assemblages of ostensibly normal tissue and bone marrow-derived (stromal) cells are recruited to constitute tumorigenic microenvironments. Most of the hallmarks of cancer are enabled and sustained to varying degrees through contributions from repertoires of stromal cell types and distinctive subcell types. Their contributory functions are becoming increasingly better understood, as are their reciprocal communications with neoplastic cancer cells that mediate their recruitment, activation, programming, and persistence [43].

Such complicated traits cannot belong to a lone cell. Moreover, their acquisition cannot be achieved by a single mutation. This conclusion discredits the basis of the somatic mutation hypothesis but supports the compromising idea of cancer occurring as a consecutive accumulation of mutation upon mutation on a single normal cell [43;44]. The new versions of the somatic mutation hypothesis do not discuss cancer transmission between humans, either.

Cancerous tumors are composed of multiple cell types: stromal, immune or malignant. Malignant cells can also show sub-clonal heterogeneity, where different clones carry various somatic mutations and show variable oncogenic potential or drug sensitivity. Finally, this sub-clonal population can change during the progression of the cancer [45]. Cancer is sustained by the production of aberrant 
cells that vary in many morphological and physiological properties. The repopulation dynamics of 150 single lineages from ten human colorectal cancers were followed. The revealed functional heterogeneity of the cell lineages varied with respect to their distinctive structural or physiological functions and potentials. Some clones were able to become dormant and undetectable only to become abundant in later generations [42].

Heterogeneity within a few tumor cell lineages may also determine the differences within the types of tumors and their locations. Cancer maintains its heterogeneous structural stability through many generations. The diversity of cancer composition remains stable over its sequential long-term propagation [42]. The presence of various slow-growing dormant clones was also evidenced by the reemergence of previously minor clones after chemotherapy and by their ability to initiate new tumors (although of a smaller size) over subsequent transplantations of the tumors in experiments [46].

Incipient micro-populations of cancerous cells are formed, distributed and dispersed in the afflicted body before postnatal ontogenesis in the form of distantly separated micro-populations. Their initial sizes are different but very small. The cancerous subunits are dispersed throughout the body either stochastically or in a manner not yet understood. Accordingly, the formation of subunits before postnatal ontogenesis is the reason they are not eliminated by the mechanisms of adaptive immunity performed by the lymphatic system [6].

It was supposed that cancerous units in primordially different locations become clinically detectable at different times after the initiation of malignant growth; this allows for the differences in their initially smaller sizes. The differences in initial cancer cell masses and their subunits throughout the body predestine individual diversity in the course and severity of cancer when the disease begins to develop [5].

At a relevant time in a victim's life, the uncontrollable growth of such micro-subpopulations becomes visible in the form of detectable extra cell masses of cancerous tissue, i.e., malignant tumors. The largest of the primordial subpopulations achieves the size of a detectable tumor far earlier than the smaller one does, thus forming the first apparent cell mass, usually called the 'primary' tumor. The subpopulations of initially lesser sizes may become visible in the form of 'secondary' detectable tumors.

\subsection{Dispersion of Cancerous Units throughout a Human Body}

Immediately following fertilization, the zygote undergoes a series of extremely rapid mitotic divisions (cleavages) wherein the enormous volume of its cytoplasm is divided into numerous smaller cells (blastomeres). In the case of the carcinogenic zygote, some of the blastomeres may contain cancerous components in their genomes.

By the end of cleavage, the blastomeres form an unfilled spheroid known as a blastula and then change their positions relative to one another. This series of extensive cell rearrangements leads to the formation within the embryonic entity of three germ layers: the ectoderm, the endoderm, and the mesoderm. The layers interact with one another and rearrange themselves to produce tissues and organs. The developing entity enters the stage of organogenesis.

During organogenesis, certain cells undergo long migrations from their places of origin to their final locations. These migrating cells include the precursors of blood cells, lymph cells, pigment cells, and gametes. Many organs are formed of cells from more than one germ layer. For instance, most facial bones are derived from cells that have migrated ventrally from the dorsal region of the head. A specialized portion of zygote cytoplasm gives rise to cells that are the precursors of the gametes (the sperm and egg).

The gametes and their precursor cells are set aside for the function of reproduction. The separation of somatic cells (which give rise to the individual body) and germ cells (which contribute to the formation of a new generation) is often one of the first differentiations to occur during animal development. The germ cells eventually migrate to the gonads, where they differentiate into gametes. The development of gametes is usually not completed until the organism has become physically mature. Gametogenesis begins during development but is completed in sexually mature adults. At maturity, the gametes may be released and participate in fertilization to begin a new embryo.

At least two paradoxes can be observed in the disposition of either primordial or later-appearing malignant tumors. First, in contrast to the assumed ubiquity of primordial tumors, there are both more 
favorite and far less favorite sites of their dispositions. The primordial tumors are primarily disposed in the prostate, lung, bronchus, colon, urinary bladder, skin, kidney, rectum, pancreas, and stomach. Moreover, the hypopharynx, bones and joints, floor of the mouth, nasopharynx, gallbladder, oropharynx, oral cavity, trachea, peritoneum and pleura are far less favorable for the disposition of primary tumors (Table 3 ).

Table3. Opposite rates of male cancer incidence by primary site and race (Rates are per 100,000 persons of the 2000 U.S. standard population) [5]

\begin{tabular}{|c|c|c|c|c|}
\hline & Cancer sites & All Races & White & Black \\
\hline \multicolumn{5}{|c|}{ Sites of Highest Rates } \\
\hline 1. & Prostate & 156.9 & 145.0 & 226.0 \\
\hline 2. & Lung \& Bronch & 85.0 & 79.9 & 95.1 \\
\hline 3. & Colon & 36.9 & 36.0 & 46.1 \\
\hline 4. & Urinary Bladder & 36,0 & 37.9 & 18.3 \\
\hline 5. & Skin & 25.6 & 28.0 & 2.0 \\
\hline 6. & Non-Hodg. Lym. & 22.6 & 23.1 & 16.0 \\
\hline 7. & Kidney & 20.8 & 20.7 & 23.1 \\
\hline 8. & Rectum & 15.8 & 15.5 & 15.9 \\
\hline 9. & Pancreas & 13.2 & 13.0 & 15.7 \\
\hline 10. & Stomach & 9.2 & 8.1 & 15.5 \\
\hline \multicolumn{5}{|c|}{ Sites of Lowest Rates } \\
\hline 1. & Hypopharynx & 1.2 & 1.1 & 2.4 \\
\hline 2. & Bones/Joints & 1.1 & 1.1 & 0.8 \\
\hline 2. & Mouth & 0.9 & 0.9 & 1.1 \\
\hline 4. & Nasopharynx & 0.8 & 0.7 & 1.1 \\
\hline 5. & Gallbladder & 0.8 & 0.6 & 1.1 \\
\hline 6. & Oropharynx & 0.7 & 0.7 & 1.2 \\
\hline 7. & Oral cavity & 0.4 & 0.4 & 0.6 \\
\hline 8. & Trachea & 0.3 & 0.3 & 0.2 \\
\hline 9. & Peritoneum & 0.1 & 0.1 & 0.1 \\
\hline 10. & Pleura & 0.0 & 0.0 & 0.1 \\
\hline
\end{tabular}

Second, the most common sites where the late-appearing tumors dispose are the lungs, bones, liver, and brain. Other places in the body are far less accessible for appearing tumors (Figure 7). One question arises immediately: Are these unfavorable places immune to the invasion of cancer? This variation and the reasons for it have not yet been discussed.

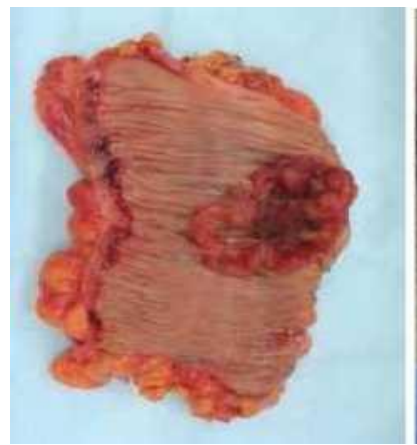

a

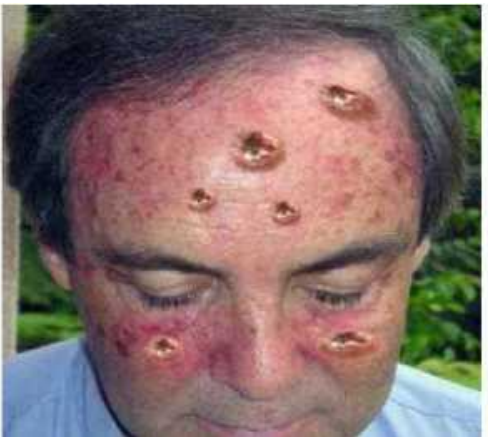

b

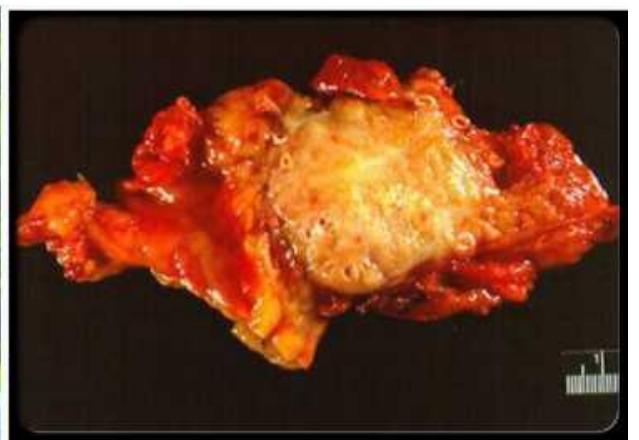

c

Figure7. Variants in the dispersion of cancerous tumors

(a) Cancer disposed on normal colon tissue (photograph courtesy of adruniverse.blogspot.com)

(b) Multiple cancer subunits on facial skin (photograph courtesy of adruniverse.blogspot.com)

(c) Cancer (yellow color) that intruded the pancreas (photograph courtesy of eMedicineHealth Image Collection Gallery)

Over the stages of organogenesis, the earliest primordial cancerous cells are carried to different areas of the embryo's body before postnatal ontogeny in the same manner that is used to create other embryonic tissues and organs. At the end of their dispersion and initial multiplication, the cells exist as the primordia of future tumors, sleeping cell masses of smaller but different sizes. The carcinogenic components in the cell genomes may dispose at various places of the afflicted entity, likely according 
to their intrinsic predilection. Then, the cells continue to exist inside the infected body in the form of several distantly separated micro-populations, i.e., the cancerous subunits, and are provided with lifesupporting materials and energy by the organism. The development of a detectable tumor is usually delayed for decades.

At the appropriate time of the host's life (primarily after 40 years of age), likely according to a specific program of cancer ontogenesis and aging, the potentially cancerous micro-populations receive their specific impulse to awaken. This means that human cancer possesses its own schedule, an intrinsic biological watch, i.e., the genetic program of its development from zygotes and primordial cancerous cells to transmission between humans. This programmed cancer subsistence is different from that of its victim. This is a specific cancerous germ line: the lineage of cells culminating in germ cells. The possession of these unique genomic traits provides cancer many benefits of undoubtedly adaptive importance. The program favors cancerous cell lineages whose schedule of life does not allow for the early restriction of reproductive or transmissive, functions of the afflicted person, and the period of its effective care for offspring before its victim is 40 years of age.

An analogous phenomenon of a mosaic disposition has a brilliant track record in the fields of infectious diseases. Similar to clones susceptible to infectious agents, any aberrant cell clones are usually present among the clones of habitual cells but in a far lesser quantity [16;47]. In one case of sickle cell anemia, aberrant erythrocytes consisted of 22 percent of the total number of red blood cells. An analogous phenomenon of dispersion mosaicism has a brilliant track record in the fields of infectious diseases. Individual variations in the sizes and focal locations of relevant susceptible cell clones can also be observed in many infectious diseases (Figure 8).

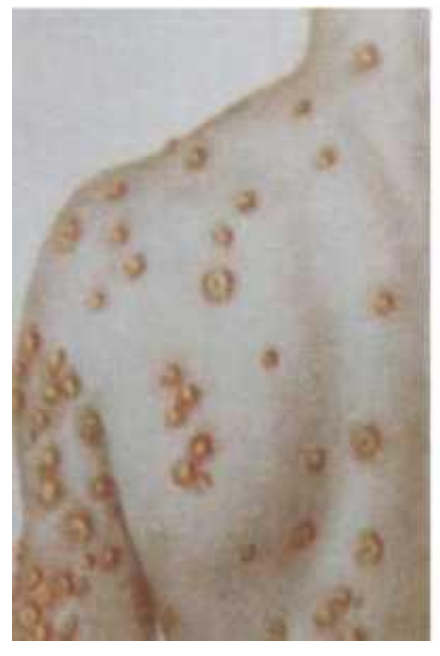

1

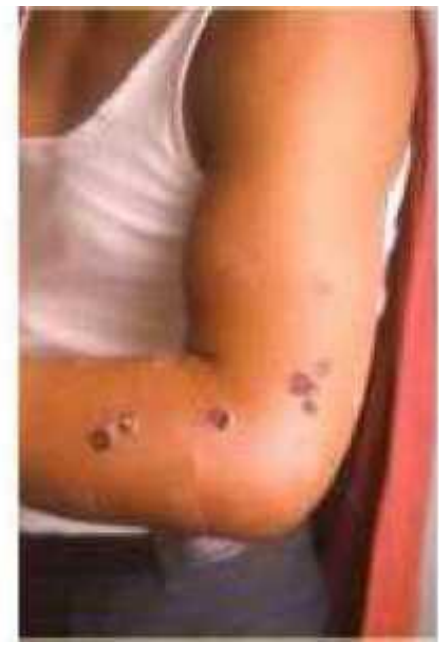

2

Figure8. Dapple dispersion of susceptible cell clones revealed by smallpox (1) and anthrax (2) infections.

The dispersion of observed clones can be extremely variable in the number and size of locations. The number of patches may be less than a dozen in a minor illness, or they may number in the thousands in a more severe case of the same type of disease. Beyond the edge of the aberrant location, the regular tissue is normal. All the discussed traits of the dispersion of cell clones susceptible to relevant infectious agents (their locations, numbers and sizes) are formed before postnatal ontogenesis [16;48]. This may mean that the distribution of aberrant clones is programmed by genomes. Cancerous cells also appear in and stochastically disperse around the victim's body before postnatal ontogenesis and initially exist in it as subpopulations (units) of smaller but different sizes. For instance, prostate cancer is a form of malignancy that primarily develop0393s in the prostate. Its additional units become visible later and are primarily located in the bones and lymph nodes. Prostate cancer tends to develop in men over the age of 50 [49]. The genomic roots of these traits should be subject to special investigation. In contrast to their steadfast locations, cancerous units enlarge during their postnatal life. The primordial and late-appearing subpopulations of cancerous cells and the tumors formed by them far later reside stably in their initial places in different areas of the body. They do not metastasize. In reality, we can observonly the non-simultaneous appearance of several identical tumors in different parts of a diseased body. An explanation of the reasons and propelling forces of cancer's discretion has been proposed and developed only recently $[4 ; 6 ; 8]$. 


\section{Progression of Cancer Within a Victim's Body}

\subsection{Self-regulation of Cancer}

Usually, cancer consists of separate units that are dispersed throughout the victim's body. However, they keep their physiological unity, as demonstrated by the set of unique traits recently evidenced in post-surgical and experimental observations.

\subsection{Communication between Cancerous Units}

The existence of inter-tumor communication was hypothesized in [50] and confirmed in a host of other studies, many of which are reviewed in [6;51]. It was noted that large tumors inhibit the growth of smaller tumors and thwart the inception of new tumors [51-53]. The extirpation of larger tumors triggers the accelerated proliferation of smaller, dormant or slower growing cancerous units. The removal of the primary tumor could accelerate the growth of previously inhibited subunits. The accelerated progression of cancerous units after foregoing resection was noted in experimental [54-56] and clinical [57;58] studies.

Acceleration in the rate of growth of secondary subunits was found after a $70 \%$ resection of cancerous liver [59]. The resection of other primary tumors was followed by a 32 -fold increase in the rate of the growth of secondary tumors.[60]. More importantly, the early extirpation of the first apparent cancer unit does not prevent the subsequent appearance of "secondary" units [60-62]. This may indicate that at the time of the resection, the secondary tumors already existed in the form of undetectable micropopulations.

It is proposed that tumors produce humoral factors that are able either to promote or to inhibit tumor growth and angiogenesis. The removal of the primary tumor reduces the production of growth inhibitors, pro-apoptosis factors and signals and thereby accelerates the growth of smaller subunits [60].

This important finding has been directly confirmed in a number of well-documented clinical case studies involving various types of cancer. For instance, in eight cases of testicular cancer, the resection of voluminous tumors caused a dramatic exacerbation of the disease [63]. The excision of primary melanomas precipitated the appearance of new subunits in three skin cancer patients $[64 ; 65]$. In one case of pancreatic cancer, excision of the primary adenocarcinoma caused the appearance in the liver of numerous previously undetectable subunits [66].

A woman diagnosed with breast cancer had a tumor $10.3 \mathrm{~cm}^{3}$ in volume. The tumor was resected. However, eight years after the resection, 37 previously undetectable cancerous units were discovered in her bones, lungs, lymph nodes and soft tissue. The volume of 31 bone tumors varied from 1.69 to $22.96 \mathrm{~cm}^{3}$. Three lung tumors varied from 1.30 to $7.26 \mathrm{~cm}^{3}$, two lymph node tumors were 2.85 and $9.66 \mathrm{~cm}^{3}$, and one tumor was $11.41 \mathrm{~cm}^{3}$. In two other breast cancer patients, 20 and 15 bone tumors became detectable five and a half years and nine months after primary resection,

respectively [60].

Thus, the life of all subpopulations of cancerous cells is controlled by their own united physiological mechanism that maintains the whole structure of cancer within a genetically predetermined size. The destruction of one or more subunits boosts the growth of the others. The set of separated subunits functions as the integral whole does, a physiologically and ecologically united organism consisting of many identical suborganisms. This can be considered a type of multicellular superorganism.

\subsection{Physiological Synchronization between Cancerous Units}

Human cancer possesses its own schedule (the program of ontogenesis) and ability for physiological synchronization between its distant separated units. The existence of these intrinsic traits has been presented and discussed in detail $[4 ; 6 ; 8 ; 12]$. It was proposed that cancer genomes contain a functional program of development, alternating its successive forms over time. The existence of these traits has been supported by both clinical observations and experiments $[4 ; 6 ; 8 ; 12]$.

\section{Self-Procurement of CANCER}

As most other living beings do, the cancerous entity is a heterotroph that sustains itself at the expense of substances and energy derived from its environments, i.e., from the body of its prey. Any individual cancer exists as a case of natural ecological relations between two living species in which 
the consumer obtains the energy for its life at the expense of substances and physiological functions composed of the consumed (the victim). Furthermore, the populations of cancerous cells subsist on life-supporting functions (nutrition, respiration, circulation of blood and lymph nodes) belonging to the victim. Thus, as any other internal parasite is, cancer is a type of ultimate parasite. Many evolutionary adaptations of cancer are due to the management of its own nutrition.

The extraction of nutrients from a .victim's body by cancerous cells is extraordinarily intense and thus is a leading cause of poor quality of life, poor physical function, and poor prognosis in cancer patients [67]. Cancer's self-provision nutrients cause damage to the victim, reduces the victim's vitality and finally leads to death. Human cancer is a highly exceptional man-eater.

\section{Effect of Cancer on a Victim's Body - Cancerous Cachexia}

Multiple complex interactions among cancer and its prey are performed exclusively by molecules by which cancer can influence its victim and affect his or her structures and functions. This complex is now only beginning to be elucidated. Solid cancers cannot grow beyond a certain size without an adequate blood supply [68]. The hypothesis that tumors produce a diffusible 'angiogenic' substance was put forward in 1968 [69]. Cancer units produce humoral, i.e., molecular factors that are able both to induce and to promote angiogenesis (Hanin, 2013) individually and thus perform an "angiogenic switch" of their own unrestricted growth.

The development of cancerous disease is induced by the primordial existence in the afflicted organism of a symbiotic population of cancerous cells. The population exists inside the afflicted organism similar to a sponge. It develops intensively at the expense of both the structures (proteins, lipids, saccharides) and functions (the supply of oxygen, nutritive substances and means for reproduction) of the host's organism. The cells are able to produce molecular agents specifically targeted on the enzymatic splitting of muscle proteins. Moreover, cancerous cells are able to secrete lipolytic enzymes, the functions of which make a substantial investment in the creation of cancerous cachexia.

Angiogenesis is a critical, rate-limiting step in the multi-stage process, leading to a detectable cancerous unit. The induction of angiogenesis is an important step in carcinogenesis. This angiogenic activity first appears in a subset of hyperplastic islets before the onset of tumor growth [70]. An angiogenic switch causes the tumor to advance down the progression pipeline [71]. One can hypothesize that it is a specific cancerous vascular endothelial growth factor, a signal protein produced by cells that stimulates vasculogenesis and angiogenesis and restores the oxygen and nutrient supply to cancerous units when the local blood circulation is inadequate.

The cancerous atrophy of skeletal muscle is characterized by an intense degradation of the macromolecules of muscle proteins and the suppression of their biosynthesis. The associated massive loss of adipose tissue is incited by the extensive degradation of fat molecules. Cancer functions as a marauder that sucks up the body of its victim until it is nearly dry. In addition, one can suppose some cyto-ecological regulators produced by cancerous cells inhibit the growth of normal cells, thus aggravating the cancerous cachexia. Some humoral agents of cancerous cells suppress the functions of the victim's cells, thus contributing to the development of cachexia [72]. However, molecular agents of this cancerous activity are still unknown.

When a victim dies of cancer, it is mostly because her tumors have exhausted her life-supporting processes and intoxicated her life-supporting organs. Cancer gobbles up its host. The development of either solitary or associated malignant tumors inevitably leads to the death of the host long before the genetically predetermined limit of her longevity. This marauding way of life exploited by cancerous tumors (the populations of cancerous cells and their subcellular structures) is performed primarily by molecular enzymatic agents either targeting the splitting of the host's macromolecules or producing a functional inhibition of their cells. The possession by cancer of such specialized and undoubtedly adaptive toxins and nutritive factors is evidence of the evolutionary origin of cancer's marauding nature.

The set of spatially separated cancer subunits functions as the integral whole, the united organism consisting of many homologous suborganisms, a type of multicellular organism. This undoubtedly adaptive trait enhances the ability of the invading parasite to colonize in the maximal quantity of locations in the victim's body that is appropriate for further development.

The earliest primordial cancerous cells settle in various areas of the embryo's body before postnatal 
ontogeny in the same manner that is used to create other embryonic tissues and organs. At the end of their dispersion and initial multiplication, the cells exist in places such as the primordiums of future tumors, small sleeping cell masses of varying sizes. The cells continue to exist within the infected body in the form of several distantly separated micro-populations, provided with life support and energy by the organism. The further progression of cancer may be delayed for decades.

At the appropriate time of the host's life, the potentially cancerous micro-populations receive a specific impulse to awaken. This means that human cancer possesses its own schedule, an intrinsic biological watch, i.e., the genetic program of its development from zygote and primordial cancerous cells to transmission between humans. This programmed cancer subsistence is different from that of its victim. This is a specific cancerous germ line: the lineage of cells culminating in the germ cells. The possession of these unique genomic traits provides cancer with many benefits of undoubtedly adaptive importance. The program favors cancerous cell lineages whose schedule of life does not allow for the early restriction of the reproductive or transmissive, functions of the afflicted person or the period of its effective care for offspring.

At the appropriate time of the host's life, the potentially cancerous micro-populations receive their specific impulse to awaken. This means that human cancer possesses its own schedule, an intrinsic biological watch; i.e., the genetic program of its development from zygote and primordial cancerous cells to transmission between humans. This programmed cancer subsistence is different of that of its victim. This is a specific cancerous germ line - the lineage of cells culminating in the germ cells. The possession of these unique genomic traits provided cancer with many benefits of undoubtedly adaptive importance. The program favors those cancerous cell lineages whose schedule of life does not allow early restriction of reproductive, or transmissive, functions of the afflicted person as well as the period of its effective care for offspring.

Cancerous cachexia is the ultimate state of cancerous disease and is characterized by cancerous cachexia, a catastrophically progressive weight loss provoked by intensive atrophy, primarily of skeletal muscle and adipose tissue, which are used as the main sources of lipids and proteins. Depending on the tumor type, weight loss occurs in 30-80\% of cancer patients and is severe (with a loss of $>10 \%$ of the initial body weight) in $15 \%$ of cases [67]. In pancreatic cancer, $85 \%$ of patients become cachectic even at diagnosis [72].

The cancerous atrophy of skeletal muscle is characterized by an intense degradation of muscle protein associated with the suppression of protein biosynthesis. The massive loss of adipose tissue is incited by extensive fat degradation. Cancer functions here as a marauder that sucks up the body of its victims until it is nearly dry. Furthermore, one can suppose some cyto-ecological regulators produced by cancerous cells inhibit the growth of normal cells, thus aggravating cancerous cachexia.

The development of this state is induced by the primordial existence of a population of xenogeneic symbiotic cells that exist inside the afflicted organism similar to a sponge. It develops intensively at the expense of both the structures (proteins, lipids, saccharides) and functions (supply of oxygen, nutritive substances and means for reproduction) of the host's organism. The cells are able to produce molecular agents specifically targeted at the enzymatic splitting of muscle proteins. Furthermore, cancerous cells secrete lipolytic enzymes, which make a substantial contribution to the creation of cancerous cachexia.

When a victim dies from cancer, it is mostly because the tumors have exhausted her life-supporting processes and intoxicated her life-supporting organs. Unfortunately, the discovery of the molecular origin of cancerous intoxication is only recent. The development of either solitary or associated malignant tumors inevitably leads to the death of the cancer's host long before the genetically predetermined limit of her longevity.

\section{Self-Reproduction OF CANCER}

\subsection{Epidemic Transmission of Cancer}

Saving and continuing its own life via self-reproduction and consequent transposition from the location of exploited resources toward unexploited ones is an extraordinarily important function of every form of living matter. Human cancer also performs these functions regularly and effectively by means of human reproductive organs and functions. This peculiar form of life is characterized by a complex of evolutionary adaptive traits necessary for the transmission of deviant genomes into 
relevant gametes, the execution of multifold acts of copulating, fertilizing, giving birth and breeding descendants to the stage of complete maturity. The absence of any of these abilities sharply diminishes the chances of the cancerous genome to prolong its life in the genomes of descendant generations.

This set of relevant functions is performed through the exploitation of the host's reproductive system. Undoubtedly, natural selection favors cancerous cell lineages whose genomic schedule of life does not restrict the reproductive, i.e., transmissible, function of the afflicted person or his care for his offspring up to the maturation of the reproductive (transmissible) stage. Furthermore, there is increasing evidence that some forms of cancer may be able to stimulate the reproductive functions of their hosts.

The risk of cervical cancer is influenced by factors related to a woman's sexual activity history, specifically, her age at her first sexual encounter and the number of her sexual partners [73]. Furthermore, a significant difference between patients and control subjects was obtained for the development of cervical cancer among wives whose husbands had had three or more extramarital sexual partners. Cervical cancer occurs most often in women who have had multiple sexual partners who have also had multiple sexual partners. It is primarily a disease that afflicts prostitutes and promiscuous women. Among sexually monogamous women, male sexual partners play a significant role in cervical carcinogenesis. When husbands had sexual relationships both before and during the marriage, their wives' risk of getting cervical cancer increased. Male promiscuity plays a significant role in the etiopathogenesis of cervical cancer. A history of sexually transmitted disease before marriage or after marriage is an important risk factor [74].

Prostate cancer is also associated with promiscuity. A new study found that promiscuity in a man's younger years could increase his risk of developing prostate cancer when he gets older. The risk of prostate cancer increases directly with the lifetime number of female sexual partners but not male partners [75]. Men reporting 25 or more sexual partners were 2.80 times more likely to be diagnosed with cancer than men with five or fewer partners [76].

Some small-sized genomic ingredients, the selfish genes, are known to be mostly benign commensal components that invade the genomes of sexual populations despite conferring no benefit to their eukaryote hosts. However, some selfish genes may be genomic parasites. They demonstrate both reproduction and transmission bias and thus confer benefits for their own existence [77]. Furthermore, according to recent observations, some selfish genes may increase the propensity of their eukaryote hosts to undergo sex with increased promiscuity; along with increased rates of non-Mendelian inheritance, this may promote spreading. These observations, along with the above-discovered association of promiscuity with the etiopathogenesis of some cancers, allow us to propose that appropriate cancerous gametes contain ingredients analogous to above-discussed selfish genes.

\subsection{The Genomic Ties of Cancer Transmission}

Infectious agents intrude next victim's body by means of the victim's ecological communications, through which the regular physiological functions are provided, for example, through feeding (as an alimentary intrusion), breathing (respiratory intrusion), direct contact and self-reproduction (venereal intrusion). Of the three, the developed the alimentary transfer of infectious agents functions the most widely and effectively [78]. Sexual intrusion is also intensive.

Before the paradigm of the parasitic nature of human cancer was developed $[4 ; 6 ; 8 ; 12]$, there were no proposed naturally occurring ways for the transmission and spread of cancer between humans. The prevailing hypothesis of a stochastic origin of any cancer out of the somatic mutation of a single cell did not allow for even the thought of cancer transmission between people.

There were rare reports of artificial cancer transmission between humans by an accidental transfer of cancer cells through organ transplantation or during surgical procedures and by the problematic transfer of cancer cells from a mother or co-twin via the placenta. Only $0.04 \%$ of organ transplant recipients contracted cancer from the donor organ. Furthermore, the survival of transplanted cancers in healthy humans is exceedingly rare and documented in only a handful of cases. Genetic immunity likely prevented such cancers from taking hold [12]. Meanwhile, human cancer is also characterized by a set of traits characteristic of malignant growth naturally transmissible among animals. Relevant information about the totality of these traits has recently been summarized and interpreted [12]. 
Undoubted analogies can be observed in the prevalence, clinical exposure and progression of disease, the origin of causative agents, and particularly in the genetic deviations characteristic of both animal and human malignancies. Any cancer sustains itself at the expense of substances in the host's body.

This set of traits includes the abnormal reproduction of aberrant cells and the consequent growth of relevant aberrant tissues in different parts of the afflicted organism. Both animal and human cancers are able of exhausting the life-supporting functions of the invaded body and intoxicating its lifesupporting organs.

Recent studies [42], together with the set of data discussed above, allow us to suppose that as any other multicellular being does, cancer contains a variety of different cells that are under different genetic regulations and possess different behaviors. Cancer consists of a few functionally heterogeneous cell lineages that vary with respect to their distinctive structural or physiological functions and potentials. The heterogeneity within tumor cell lineages may also determine the differences within the types of tumors and their locations. Cancer is able to maintain its structural stability through many generations and the diversity of cancer composition remains stable over its sequential long-term propagation [42]. Therefore, both animal and human cancers have developed many adaptations that enable these aberrant lineages of mammalian cells to exist as a multicellular parasite $[4 ; 6]$.

\subsection{Sexual Transfer of Cancer via Reproduction of its Prey}

According to the set of evidence discussed above, human cancers belong to the group of deadly invasive diseases. Infections and parasitic invasions also belong to this group. As any other deadly invasive disease does, human cancer exists as a result of natural ecological relations between two species, in which the contagious species (the consumer) obtains the matter and energy for its life, with reproduction and subsequent transmission at the expense of substances contained in the living victim. These actions exhaust the lifeblood of the afflicted body and thus restrict its vitality, provoking the state of disease and a loss of victim viability. Prey is not available for the subsistence of every cancer. Cancer must live within the exhausted victim before it dies. Consequently, the subsistence of such diseases depends on the regular transmission of the causative agent from one living victim to the next one.

The transmission of any invasive parasite inside the body of the next victim is primarily carried out by means of the victim's ecological communications, through which the regular physiological functions of nutrition, respiration, and self-reproduction are provided (alimentary, respiratory, and sexual transmission).

Transmissible canine venereal cancer is a parasitic disease of dogs and other canines. It passes from one dog to another, usually during coitus. Its invasive agents are the tumor cells themselves [79]. Some studies have estimated that the disease may have originated from a wolf or an East Asian breed of dog between 200 and 2500 years ago [79] or more than 6000 years ago, when dogs were first domesticated [80]. According to a more recent estimation, the lineage of malignant cells first arose in a dog with low genomic heterozygosity that may have lived approximately 11,000 years ago. The cancer spawned by this founder dispersed across continents approximately 500 years ago in the era of rapid human global exploration.

The genomes of cells that form the canine venereal tumor contain 1.9 million somatic substitutions in contrast to the genomes of the organisms consumed by them $[81 ; 82]$. The genomes of tumors from different cases show very little microsatellite variation. The invasive agents have gone through many remarkable adaptations that have enabled this mammalian cell lineage to live as a unicellular pathogen [80]. Although they were a massive substitution burden, these mammalian somatic cells were able to survive unchanged for millennia [81].

Coital transmission is also used by human cancer. Unlike the canine venereal tumor, the transmission of human cancer is performed not by tumor cells but by the genomic predecessors of the cancerous cells: the gametes [13;14]. The invasive agents of human cancers go through many remarkable adaptations that enable this mammalian cell lineage to live as a unicellular pathogen of mammalian origin.

At the same time, in contrast to animal cancer, the malignant disease of humans does not possess the ability to transfer its living cells from one person to another. Human cancer ensures the maintenance 
of its own life before its prey is exhausted and dies in another way. The transmission of human cancer proceeds in the form of a cancer-programmed genomic component as an intruder in the genome of the diseased person.

In evolution, human cancer developed its transmission by means of a regular way of communication between victims, i.e., sexual intercourse (Figure 9). The transfer of human cancer is also vector mediated. Functions of vectors may be performed by either male or female gametes. During the formation of the intruder zygote, the deviant components of the xenogamous genetic code appear to be included in the united genetic code. The components continue to exist in it and function over the creation of intruded cells with their plethora of both banal and unique traits. Once implanted in the genome of its current host, human cancer ensured that it would be reproduced in the genomes of children via the self-reproduction of the cancer-carrying parent. As other components of genetic code can, they were able to reproduce in the descendant genomes and thus multiply and disperse between people.

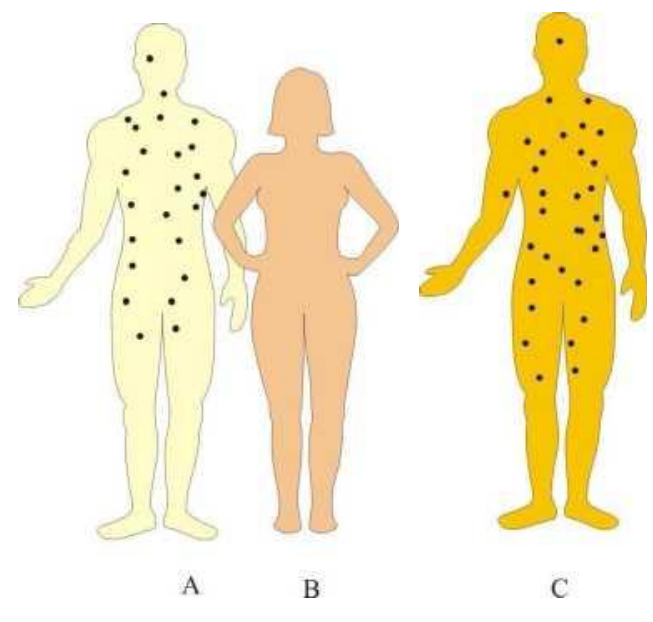

Figure9. Variant of human cancer transmission

A - The father, the carrier of cancerous gametes; the victim of cancerous disease. B - The mother, the carrier of non-cancerous ovens. C - Their son who has cancer that arose from a zygote uniting the genomes of the father's and the mother's gametes.

In contrast to canine venereal tumors, the genomes of most human cancers, with between 1000 and 5000 somatic substitutions contain several hundred times fewer somatic alterations. Approximately 20 distinct alteration signatures were found in many cancer types, whereas others were confined to a single cancer class. Hypermutation, localized to small genomic regions, or 'kataegis,' was found in many cancer types [83]. The results reveal the diversity of substitution processes underlying the genesis of cancer, with potential implications for understanding cancer etiology. The genomic carrier of human cancer can be deposited in either male or female gametes. It is characterized by a complex of traits necessary for providing the ability of precursor prey to transmit cancerous genomes into relevant gametes, to execute multifold acts of fertilization and to breed the descendants (cancerous units) to the stage usually called complete maturity. The absence of any of these abilities sharply diminishes the chances of the cancerous genome to prolong its life in the genomes of descendant generations.

\section{Natural SELECTION FOR Hereditary IMMUNity to CANCER}

Natural selection for hereditary immunity saved humankind from being annihilated by the plethora of infections that emerged over their evolution. Furthermore, infections served as epidemic movers of natural selection not only at the descent of Homo sapiens in the African savannah but also in the further evolution and diversification of humankind over its multi-millennial wandering around the world. Cancerous epidemics could perform the same function in the relation of cancerous invasion. The results of this multi-millennial selection can be observed in the existence of the individual, population, ethnic and racial differences in cancer prevalence considered above (section 3.1., Hereditary Cancer; 3.1.1., Family Observations; 3.1.2., Ethnic Observations; 3.1.2.1., Population Disparity in Cancer Prevalence; 3.1.2.2., Racial Differences in Cancer Prevalence) and in the stochastic mosaic intra-individual distribution of cancerous units inside the human body (section 
3.1.5., Phenomenon of Immune Mosaics; 3.3.3.2, Embryogenesis of Cancer; 3.3.3.2.1., Dispersion of Cancerous Units throughout a Victim's Body). Natural selection for genetic resistance (section 3.1.3., Figure 2,3) and the search for the possibility for the abruption of cancerogenesis could be performed at any stage of cancer circle of life.

\section{The Circle of Cancer Life}

The consequent events of cancer life may be present in the form of its specific circle of life. This circle can be performed by cancer inside the human body at the expense of relevant materials, energy and functions of invaded organism. The assortment of host prerequisites for the development of cancer varies over the progression of cancer.
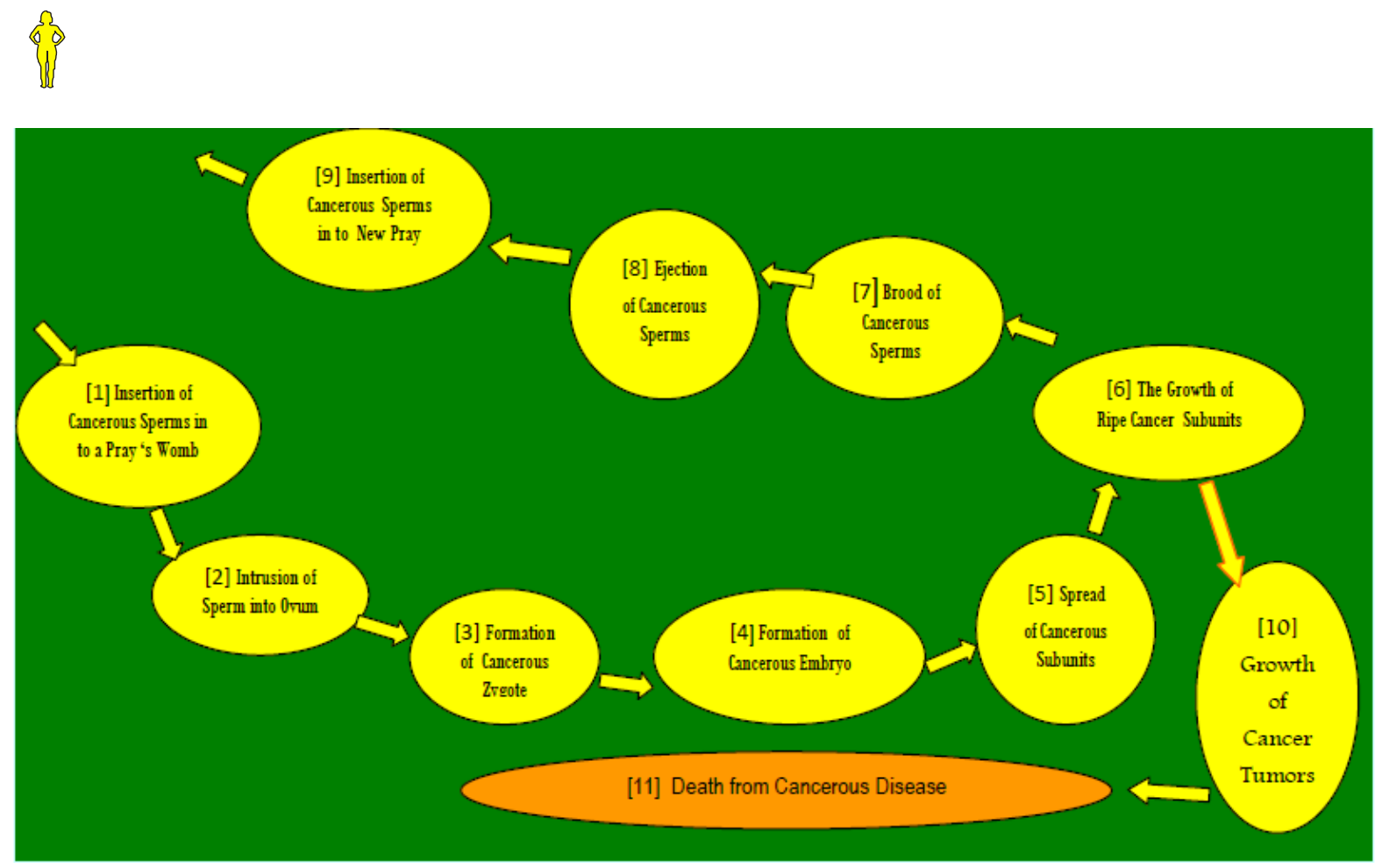

Figure10. Integrative analytical model of a cancer's circle of life

The model unites all traits and functions of cancer considered above. The evolutionary emergence of cancer was predetermined by genome transformations that created, in evolution, inter-taxon differences in the molecular constitution of the inherent physiological systems responsible for the regulation of cell division and tissue growth. As a sexually transmitted parasite of human genome, human cancer possesses a set of constitutional, adaptive, and inherently immune traits that could be the result of evolution over many millennia. The date of its initiation could be referred, for instance, to the epoch of xenogamous intercourse of Homo sapiens with Homo neanderthalensis.

\section{CONCLUSION}

The integrative investigation above was devoted to the further development of an entirely innovative hypothesis of xenogamous origin and parasitic subsistence of human cancer. The main goal of this article was to search, reveal and present a more exhaustive set of evidence of the hypothesis regarding the principal traits of both the cancer-causative agent and the cancerous disease induced by it. The investigation was grounded on a multidisciplinary integrative reassessment and reinterpretation of the present, current and newest data on cancer origin from the viewpoint of the biological circle of life of the specialized causative agent of the disease.

According to this in-depth and advanced a priori analytical investigation, any personal case of cancerous disease arises and develops as result of the invasion of a human body genome by a specialized parasite, the causative agent of the disease. The multiplicity of epidemic and clinical traits belonging to cancerous disease are performed by the specific causative agent of the disease.

The agent is a specialized biological entity that evolved to invade the human genome and to develop inside the human body at the expense of the materials, energy and coupling of functions of the 
invaded organism. Although this specific causative agent of cancerous disease is an extraordinarily dangerous lethal parasite, there is no principal originality in the few similar traits that also belong to many other widely known invasive diseases. Except for some unique biological traits, primarily those that provide cancerous disease with the ability to invade a victim genome, reproduce in it and allow cancer to be transmitted sexually to the genomes of new prey, cancer may be considered as analogous to the plethora of infectious parasites present on Earth. However, this agent is extraordinary compared with the plethora of other widely known invasive diseases. The extraordinariness begins at the discovery of its make-up. $(84,85,86)$

The core of the cancer-causative agent that consists of a set of cancerous genes may be inserted, over its evolution, from an unknown source inside the genomes of human gametes (sperm and ovum). Since that point, the parasite can subsist only inside a human body and can be transmitted between people only via conception by means of human gametes invaded by the agent. This is a parasite of the genomes of human reproductive cells (sperm, ovum) that function as primordial unicellular shelters and transmitters of the parasite.

There are enough principal traits that allow for counting this lethal invader as belonging to just forming new biological taxa: the genome-intruding parasitic selfish genes. These genomic parasites demonstrate sexual transmission bias and invade sexual populations despite conferring no benefit to their hosts. The specific causative agent of human cancerous disease can admit the first discovered and described cruel member among other known representatives of this taxon, all of which belong to indifferent symbionts. Moreover, it is the first genome intruder among a multiplicity of traditional causative agents of human invasive diseases.

The process of cancerous invasion inside the genomes of an attacked human body is initiated and performed exclusively by the mutual activity of both female and male gametes in the case when least one of which contains a cancerous genome. Fertilization led to the formation of an invaded (cancerous) zygote, the human biological entity whose genome contains both normal and cancerous genes. If cancerous genes present in both male and female gametes, their quantity and quality will differ from those in the elementary case noted above. Such primordial differences may be associated, for instance, with a known plethora of genetic diversity in the manifestations of cancerous disease revealed by clinical and epidemiological observations performed among different populations and ethnic and racial groups.

The inclusion of cancerous genes inside of zygotes allowed for the partially mutual but substantially independent development of its normal and cancerous structures. The form of a cancerous zygote is a very short stage of the maximally mutual coexistence of invasive agents and invaded persons. The structural and functional differentiation of the germ plasm and gametogenesis are performed inside of the earliest zygote simultaneously for both normal and cancerous sperm and oocyte.

In the middle of the zygote and the embryo, the crude mass of specifically invaded cancerous cells are dispersed stochastically inside the zygote forming the primordial cancerous subunits. However, it should be noted that all steps of the circle of cancer's life are performed exclusively inside the developed human body, over its zygotic, embryonal, newborn and any other successive forms in close association with the calendar dates of this process, in which its initiation should be dated by the youth of invaded organism. Thus, the age of the oocyte before invasion was decades older than that of the invader. The process will be continued over the next generation with the birth of cancerous offspring.

The dating of cancer's circle of life reveals concrete associations with the intensity of the clinical course of cancerous disease. Like many stages of disease, the primordial steps of cancer's circle of life (Insertion of Cancerous Sperm into a Prey's Womb, Intrusion of Sperm into Ovum, Formation of Cancerous Zygote, Formation of Cancerous Embryo) are also performed at the expense of the materials, energy and functions of invaded organism, but these steps are primarily on the level of cells and with the involvement of a restricted quantity of cell masses. The energy intensity of these bioecological technologies is very low. Their existence do not substantially influence the normal physiological state of the invaded person. The state does not reveal any signs of the invasion's presence at this stage of its existence.

A much higher energy intensity of cancer activity is associated with the stage of Cancer Progression within a Victim's Body. Substantial portions of energy are spent during the stage of 
the progressive growth of cancerous sub-units. The start and performance of cancer reproduction, particularly the brood of cancerous sperm and the creation and maintenance of the prey's relevant sexual status, should also be counted as the phases of the substantial energy intensity of cancer activity performed by a cancer-causative agent at the expense of the resources it retrieved from the body of its prey.

The spending of energy is performed at the expense of the materials and is the energy of the exploited prey, which is exploited by the invader. The cancerous atrophy of the prey's skeletal muscle observed at this stage is characterized by an intense degradation of the macromolecules of muscle proteins and the suppression of their biosynthesis. The associated massive loss of adipose tissue is also indicated by the progressive degradation of fat molecules. Cancer functions as a marauder that sucks up the body of its victim until it is nearly dry.

Important theoretical and practical attention is attracted to the set of questions regarding the executors of ecological and physiological functions belonging to the causative agent of cancer. Cancerous disease is a result of ecological functions performed by the subsistence of a cancerous entity inside an invaded human genome. Ecological functions of human cancer devoted to the selfprocurement of cancer characterize this invasive agent as a highly exceptional man-eater. In addition to the fermentative destruction of tissues, developing structures of cancer are able to induce intensive vascularization toward the provision of their own needs of oxygen and other life-procurable materials.

Among the pioneering conclusion of the discovery is that, as in many other invasive diseases, some epidemiological observations allow for concluding that many people possess hereditary immunity to cancer, elaborated by natural selection performed over an epidemic process. Moreover, human cancer is a biological entity foreign to the human body. The circle of cancer's life is also figured in the paradigm for the first time. Cancer subsistence begins from the initial invasion of the host's genome with a cancerous gamete. The stage of invasion is performed by means of habitual traits of the sperm that carry the set of cancerous genome. Over the following mutual embryogenesis of both the victim and the intruder, the subsistence of the latter is supported by the cancer cells' inherent possession of constitutive immunity to the host's cell-regulation management and immune defense. This aspect of cancer subsistence is crucial for the progression of cancer subunits within the prey's body. It is responsible for the pernicious effects of cancer subunits on its victim.

In many cases, cancer may consist of distantly separated units. The dispersion of cancerous units around the prey's body is performed over embryogenesis but before postnatal ontogenesis. The makeup of any cancer can be considered evidence of its source at the initial cancerous gamete. The existence of cancer as a specialized biological entity is also confirmed by the data on the selfregulation of cancer physiology and the physiological synchronization of and communication between cancerous units.

Cancer is a type of sexually transmitted disease. The transmission of cancer from one victim to another is performed through the transmission of a cancerous genome over sexual intercourse via reproduction. The transmitted cancerous genome realizes its parasitic traits in offspring and future generations. The current pandemic spread of cancer has been brought about by the growing expansion of inter-ethnic admixture favored by growing industrialization, urbanization, globalization, and migration.

These new notions provide the framework and initial landmarks for the location of genomic roots of cancer origin and should encourage new research ideas and proposals for cancer prevention and therapy. The prevention of cancer could be achieved by the voluntary restriction of xenogamous fertilization and by the orientation on non-cancerous genealogies. In fear of cancerous offspring, people should choose spouses of non-promiscuous and noncancerous genealogy. The means of preventive vaccination should be elaborated against molecular ecological agents of cancer subsistence.

Appropriate genetic and genealogical evaluations must be performed before conception. First of all, the cancerous genealogies of expectant moms and dads must be discovered in detail. Their genomes must also be tested for the risk of cancer in their potential children. The results can provide early warnings of cancer, the deadliest disease. The warnings can help people make rational decisions about their marital plan. This type of protective parenting is now on its way to becoming a mainstream medical test. 
Additionally, the hypothesis of xenogamous origin, parasitic subsistence and the pandemic spread of human cancer does not support optimistic perspectives for the healing of cancerous disease by surgical technologies. All previous efforts of medicine in chemotherapy but particularly in the surgical and radiological healing of cancer appear futile, and they were not reasoned by the biology of cancer and the pathogenesis of cancerous disease. Furthermore, the hypothesis led to the discrediting of surgical and radiological cures for cancerous disease. This negative opinion is augmented by the activation of secondary tumors after the resection of primary tumors.

The discovery of cancerous disease from the viewpoint of the biological circle of life of a specialized causative agent of the disease revealed new evidence of the hypothesis of xenogamous origin and parasitic subsistence of cancer. The multiplicity of the revealed traits of cancer causative agents and the signs of their adaptiveness should be appreciated as evidence of the deep phylogeny of cancer evolution. However, there remains much to learn about this extraordinarily unique and extremely complex disease. According to the proposed paradigm, the search for a coveted clue regarding the genomic roots of cancer and the solving of practical problems met by medicine would be oriented on the discovery of structural and functional differences between the genomes of cancerous and normal cells.

\section{REFERENCES}

[1] Torre LA et al. Global cancer statistics, 2012. 2A Cancer J Clinic 2015; 65(2):87-100.

[2] Bauer KH: Mutationstheorie der Geschswulst-Entstehung. Berlin, Springer, 1928.

[3] Globocan 2012: Estimated Cancer Incidence, Mortality and Prevalence Worldwide in 2012. 2012. Lion France, International Agency for Research on Cancer.

[4] Rumyantsev SN: The Uniqueness and Ordinariness of Cancer Origin and Pathogenesis: New Epidemiological, Clinical and Preventive Perspectives. J Clin Med Res 2009; 1(1):32-36.

[5] Rumyantsev S.N.: Functions of hereditary immunity and xenogamy in cancer origin and pandemic spread. OJI 2011; 1(2):27-40.

[6] Rumyantsev SN: Hypothesis: Towards the origin of cancer epidemics and pathogenesis. Journal of Carcinogenesis 2010; 9(2):1-7.

[7] Marshall E: Cancer Research and the $\$ 90$ Billion Metaphor. Science 2011; 331(6024):15401541.

[8] Rumyantsev SN. The Discredit of Cancer Metastasis. http://www.scienceboard.net /community/perspectives.227.html . 2009. Science Advisory Board [http://www. Scienceboard .net/community/perspectives.227.html].

[9] Rumyantsev S.N.: Cancer Progression from Cancerous Gamete to Advanced Tumors. North American Open Cancer Research Journal 2015; 1(1):1-22.

[10] Rumyantsev SN: Cancer; Hereditary Immunity: Fundamental Principles and Exploitation in Life Study and Health Care. New York, Nova Biomedical Books, 2008, pp 210-212.

[11] Rumyantsev SN. The Collapse of Cancer Metastases Hypothesis. The Announcement of New Study Results. (PRWEB) . 2010.

[12] Rumyantsev SN: Toward the genomic roots of cancer. Journal of Medicine and Medical Sciences 2012; 3(10):638-659.

[13] Rumyantsev SN: Human Cancer is a Parasite Spread via Intrusion in Genome . Pure Appl Bio 2013; 2(1):7-16.

[14] Rumyantsev SN: Human cancer is transmitted via genome. OJGen 2013; 3:6-11.

[15] Rumyantsev SN: Evolutionary adaptations of human cancer for parasitic life. Open Journal of Immunology 2013; 3(2):54-61.

[16] Rumyantsev SN, Gerasimov VK: The Origin and Functions of Biodiversity in Infectious and Non-Infectious Diseases; in: Schwartz J, (ed): Focus on Biodiversity Research. Nova Science Publishers, 2007, pp 199-300.

[17] Rumyantsev S: Phenomenon of Immune Mosaicism; Hereditary Immunity: Fundamental Principles and Exploitation in Life Study and Health Care. Nova Science Publishers, New York, 81-102. New York, NY, Nova Science Publishers, 2008, pp 81-102. 
[18] Warthin AS: Hereditary with reference to carcinoma as shown by the study of the cases examined in thepathological laboratory of the University of Michigan, 18951913. Archives of Internal Medicine 1913; 12:546-555.

[19] Warthin AS: The further study of a cancer family. J Cancer Research 1925; 9(279):286.

[20] Hauser J, Weller CV: A Further Report on the Cancer Family of Warthin. Am J Cancer 1936; 27(3):434-450.

[21] Boland CR and Lynch HT: The History of Lynch Syndrome. Fam Cancer 2013; 12(2):145-157.

[22] Cancer death rates among 50 countries. National Cancer Institute, editor. World Health Organization. 1992. American Cancer Society.Ref Type: Electronic Citation

[23] Haiman CA, Chen GK, Blot WJ, Strom SS, Berndt SI, et al: Characterizing Genetic Risk at Known Prostate Cancer Susceptibility Loci in African Americans. PLoS Genet 2011; 7(5).

[24] International Range of Cancer Incidence. National Cancer Institute, editor. http://rex.nci.nih.gov/NCI_Pub_Interface/raterisk/rates24.html.1992. World Health Organization.

[25] Ahlbom A, Lichtenstein P, Malmstrцm H, Feychting M, Hemminki K, Pedersen NL: Cancer in twins: genetic and nongenetic familial risk factors. J Natl Cancer Inst 1997; 89(4):287-293.

[26] Neale RE, Mineau G, Whiteman DC, Brownbill PA, Murphy MF: Childhood and adult cancer in twins: evidence from the Utah genealogy. Cancer Epidemiol Biomarkers Prev 2005; 14(5):12361240.

[27] Hemminki K, Li X: Cancer risks in twins: results from the Swedish family-cancer database. Int J Cancer 2002; 99(6):873-878.

[28] Hjelmborg JB, Scheike T, Holst K, Skytthe A, Penney KL, Graff RE, Pukkala E, Christensen K, Adami HO, Holm NV, Nuttall E, Hansen S, Hartman M, Czene K, Harris JR, Kaprio J, Mucci LA: The heritability of prostate cancer in the Nordic Twin Study of Cancer. Cancer Epidemiol Biomarkers Prev 2014; 23(11):2303-2310.

[29] Rumyantsev SN: Bioecology of pleistocenic spurt in anthropogenesis. Int J Integ Biol 2010; 10(1):14-21.

[30] Rumyantsev SN: The intra-individual diversity in senescence. Biogerontology 2003; 4:171-178.

[31] Avise IJ: Clonality:The Genetics, Ecology, and Evolution of Sexual Abstinence in Vertebrate Animals. Oxford University Press, USA., 2008.

[32] Rumyantsev SN: The origin of individual differences in the course and severity of diseases. TheScientificWorldJOURNAL (in press) 2006; 6:1674-1704.

[33] Gilbert S.F: Developmental Biology. ed 6th, Sunderland, Massachusetts, Sinauer Associates,Inc., 2000.

[34] Albiges L, Molinie V, Escudier B: Non- clear cell renal cell carcinoma: does the Mammalian target of rapamycin represent a rational therapeutic target? Oncologist 2012; 17:1051-1062.

[35] Briasoulis E, Pavlidis N: Cancer of Unknown Primary Origin. The Oncologist 1997; 2(3): 142152.

[36] McCulloch M, Jezierski T, Broffman M, Hubbard A, Turner K, Janecki T: Diagnostic accuracy of canine scent detection in early- and late-stage lung and breast cancers. Integrative Cancer Therapies 2006; 5:30-39.

[37] Soerjomataram I, Coebergh JW: Epidemiology of multiple primary cancers. Methods Mol Biol 2009; 471:85-105.

[38] Levi F, Randimbison L, Te VC, Conconi MM, La Vecchia C: Risk of prostate, breast and colorectal cancer after skin cancer diagnosis. Int JCancer 2008; 123:28993001 .

[39] Milan T, Pukkala E, Verkasalo PK, Kaprio J, Jansen CT, Koskenvuo M, Teppo L: Subsequent primary cancers after basal-cell carcinoma: a nationwide study in Finland from 1953 to 1995. Int J Cancer 2000; 87:283-288.

[40] Nugent Z, Demers AA, Wiseman MC, Mihalcioiu C, Kliewer EV: Risk of second primary cancer and death following a diagnosis ofnonmelanoma skin cancer. Cancer Epidemiol Biomarkers Prev 2005; 14:2584-2590.

[41] Soerjomataram I, Louwman WJ, Lemmens VE, Coebergh JW, de Vries E: Are patients with skin cancer at lower risk of developing colorectalor breast cancer? Am J Epidemiol 2008; 167:14211429. 
[42] Kreso A, O'Brien CA, van Galen P, Gan OI, Notta F, Brown AM, Ng K, Ma J, Wienholds E, Dunant C, Pollett A, Gallinger S, McPherson J, Mullighan CG, Shibata D, Dick JE: Variable clonal repopulation dynamics influence chemotherapy response in colorectal cancer. Science 2013; 339(6119):543-548.

[43] Hanahan D, Coussens L.M: Accessories to the crime: functions of cells recruited to the tumor microenvironment. Cancer Cell 2012; 21:309-322.

[44] Hanahan D, Weinberg R.A: Hallmarks of cancer: the next generation. Cell 2011; 144:646-674.

[45] Mardis E.R.: Genome sequencing and cancer. Current Opinion in Genetics \& Development 2012; 22:245-250.

[46] Marusyk A, Polyak K: Cancer. Cancer cell phenotypes, in fifty shades of grey. Science 2013; 339(6119):528-529.

[47] Rumyantsev SN: Chemical ecology and biomolecular evolution. Acta Biotheor 1997; 45:65-80.

[48] Rumyantsev SN: Hereditary Immunity: Fundamental Principles and Exploitation in Life Study and Health Care. New York, Nova Biomedical Books, 2008.

[49] Siegel R: Cancer statistics, 2011: the impact of eliminating socioeconomic and racial disparities on premature cancer deaths. CA Cancer Journal for Clinicians 2011; 61:212-236.

[50] Prehn RT: Two competing influences that may explain concomitant tumor resistance. CancerRes 1993; 53:3266-3269.

[51] Retsky M, Demicheli R, Hrushesky W, Baum M, Gukas I: . Surgery triggers outgrowth of latent distant disease in breast cancer: An inconvenient truth? 2010; 2: 305-37. Cancers 2010; 2:305.

[52] Baum M, Chaplain M, Anderson A, Douek M, Vaidya JS: Does breast cancer exist in a state of chaos? Eur J Cancer 1999; 35:886-891.

[53] Demicheli R, Retsky M, Hrushesky WJM, Baum M, Gukas ID: The effects of surgery on tumor growth: a century of investigations. 2008; 19: 1821-8. Ann Oncol 2008; 19:1821-1828.

[54] de Jong KP, Lont HE, Bijma AM, Brouwers MA, de Vries EG, van Veen ML, Marquet RL, Slooff MJ, Terpstra OT: The effect of partial hepatectomy on tumor growth in rats: in vivo and in vitro studies. Hepatology 1995; 22:1263-1272.

[55] Garcia-Alonso I, Palomares T, Alonso A, Portugal V, Castro B, Carames J, Mendez J: Effect of hepatic resection on development of liver metastasis. Rev Esp Enferm Dig 2003; 95:765-767.

[56] Ikeda Y, Matsumata T, Takenaka K, Sasaki O, Soejima K, Sugimachi K: Preliminary report of tumor metastasis during liver regeneration after hepatic resection in rats. Eur J Surg Oncol 1995; 21:188-190.

[57] Elias D, De Baere T, Roche A, Ducreux M, Leclere J, Lasser P: During liver regeneration following right portal embolization growth rate of liver metastases is more rapid than that of the liver parenchyma. Br J Surg 1999; 86:784-788.

[58] von Schweinitz D, Fuchs J, Gluer S, Pietsch T: The occurrence of liver growth factor in hepatoblastoma. Eur J Pediatr Surg 1998; 8:133-136.

[59] Sorin V, Mizrahi A, Ohana P, Ayesh S, Birman T, Hochberg A, Czerniak A: Partial Hepatectomy in rats results in significant growth of liver metastases by increased expression of H19 gene. Cancer Therapy 2009; 7:240-244.

[60] Hanin L, Korosteleva O: Does extirpation of the primary breast tumor give boost to growth of metastases? Evidence revealed by mathematical modeling. Math Biosci 2010; 223(2):133-141.

[61] Giuliano AE, Hunt KK, Ballman KV, Beitsch PD, Whitworth PW, Blumencranz PW, Leitch AM, Saha S, McCall LM, Morrow M: Axillary dissection vs no axillary dissection in women with invasive breast cancer and sentinel node metastasis: a randomized clinical trial. JAMA 2011; 305(6):569-575.

[62] Pockaj BA, Wasif N, Dueck AC, Wigle DA, Boughey JC, Degnim AC, Gray RJ, McLaughlin SA, Northfelt DW, Sticca RP, Jakub JW, Perez EA: Metastasectomy and surgical resection of the primary tumor in patients with stage IV breast cancer: time for a second look? Ann Surg Oncol 2010; 17(9):2419-2426.

[63] Lange PH, Hekmat K, Bosl G, Kennedy BJ, Fraley EE: Accelerated growth of testicular cancer after cytoreductive surgery. Cancer 1980; 45:1498-1506. 
[64] De Giorgi V, Massi D, Gerlini G, Mannone F, Quercioli E, Carli P: Immediate local and regional recurrence after the excision of a polypoid melanoma: Tumor dormancy or tumor activation? 2003; 29, 664-7. Dermatologic Surgery 2003; 29:664-667.

[65] Tseng WW, Doyle JA, Maguiness S, Horvai AE, Kashani-Sabet M, Leong SPL: Giant cutaneous melanomas: evidence for primary tumour induced dormancy in metastatic sites? Br Med J 2009; Case Reports(October 5 ).

[66] Deylgat B, Van Rooy F, Vansteenkiste, Devriendt D, George C: Postsurgery activation of dormant liver micrometastasis: a case report and review of literature , , Devriendt D, George C. J Gastrointest Canc 2011; 42:1-4.

[67] DeWys WD, Malone WF, Butrum RR, Sestili MA: Clinical trials in cancer prevention. Cancer 1986; 58(8 Suppl):1954-1962.

[68] Carmeliet P, Rakesh KJ: Angiogenesis in cancer and other diseases. Nature 2000; 407: 249-257.

[69] Ehrmann RL, Knoth M: Choriocarcinoma: transfilter stimulation of vasoproliferation in the hamster cheek pouch studied by light and electron microscopy . J Natl Cancer Inst 1968; 41:1329-1341.

[70] Folkman J, Watson K, Ingber D, Hanahan D: Induction of angiogenesis during the transition from hyperplasia to neoplasia. Nature 1989; 339(6219):58-61.

[71] Hanin L: Seeing the invisible: how mathematical models uncover tumor dormancy, reconstruct the natural history of cancer, and assess the effects of treatment. Adv Exp Med Biol 2013; 734:261-282.

[72] Tisdale MJ: Pathogenesis of cancer cachexia. J Support Oncol 2003; 1(3):159-168.

[73] Skegg D.C.G, Corwin P.A, Paul C, Doll R: Importance of the male factor in cancer of the cervix. Lancet 1982; 2:581-583.

[74] Shyman S, Aganoal S.S, Sehgal A, Sardana S, Kumar A, Luthra U.K: Role of Male Behavior in Cervical Carcinogenesis among Women with One Lifetime Sexual Partner. Cancer 1993; 72:1666-1669.

[75] Rosenblatt K.A., Wicklund K.G, Stanford J.L: Sexual factors and the risk of prostate cancer. American Journal of Epidemiology 2001; 153:1152-1158.

[76] Sarma A.V. et al.: Sexual behavior, sexually transmitted diseases and prostatitis: the risk of prostate cancer in black men. Journal of Urology 2006; 176:1108-1113.

[77] Werren J.H.: Selfish genetic elements, genetic conflict, and evolutionary innovation. Proceedings of the National Academy of Sciences of the United States of America 2011; 108 :1086370(Suppl 2):10863-10870.

[78] Burgasov PN, Rumyantsev SN: Evolution of Clostridiosis [in Russian]. Moscow, Meditsine, 1974.

[79] Murgia C, Pritchard JK, Kim SY, Fassati A, Weiss RA: Clonal origin and evolution of a transmissible cancer. Cell 2006; 126:477-487.

[80] Rebbeck C.A. et al.: Origins and evolution of a transmissible cancer. Evolution 2009; 63:23402349.

[81] Murchison E.P. et al.: Transmissible Dog Cancer Genome Reveals the Origin and History of an Ancient Cell Lineage. Science 2014; 343:437-440.

[82] Murchison EP: Clonally transmissible cancers in dogs and Tasmanian devils. Oncogene 2008; 27(S2):S19-S30.

[83] Alexandrov L.B. et al.: Signatures of mutational processes in human cancer. Nature 2013; 500:415-421.

[84] Rumyantsev SN. More than 12,000 years with AIDS (deciphering of genetic relicts). 7th International Congress of Genetics , 156. 1993. Ref Type: Abstract

[85] Rumyantsev SN: Dating of First Emergence of Human Infections. Journal of Medicine and Medical Sciences 2012; 3(6):423-433.

[86] Rumyantsev SN: Where and When Human Viral Epidemics First Emerged. British Journal of Medicine \& Medical Research 2012; 2(4):647-661. 